Access the official formatted version through http://onlinelibrary.wiley.com/journal/10.1111/(ISSN)1523-1739

\title{
Resolving future fire management conflicts using multi-criteria decision making
}

Running head: Resolving fire management conflicts

Keywords: multi-criteria decision analysis (MCDA), structured decision making, fuel reduction, prescribed burning, wildland-urban interface WUI

Word Count: 5995

\section{Authors}

Don A. Driscoll ${ }^{\mathrm{a}, \mathrm{b}}$, Michael Bode ${ }^{\mathrm{a}, \mathrm{c}}$, Ross A. Bradstock ${ }^{\mathrm{d}}$, David A. Keith ${ }^{\mathrm{e}, \mathrm{f}}$, Trent D. Penman $^{\mathrm{d}, \mathrm{g}}$, Owen, F. Price ${ }^{\mathrm{d}}$.

a. National Environmental Research Program Environmental Decisions Group and ARC Centre of Excellence for Environmental Decisions, Australia

b. Fenner School of Environment and Society, Australian National University, ACT, 0200, Australia

c. School of BioScience, University of Melbourne, Parkville, Vic 3010, Australia

d. Centre for Environmental Risk Management of Bushfires, Institute of Conservation Biology and Environmental Management, University of Wollongong, NSW 2522, Australia

e. NSW Office of Environment \& Heritage, Hurstville, NSW 2220, Australia

f. Centre for Ecosystem Science, School of Biological Earth \& Environmental Science, University of New South Wales, Sydney, NSW 2052, Australia

g. School of Forest and Ecosystem Science, University of Melbourne, Water Street, Creswick, VIC 3363,

Australia

Corresponding Author: Don A. Driscoll. Fenner School of Environment and Society, Australian National University, ACT, 0200, Australia. don.driscoll@anu.edu.au, +61 2 61258130. 


\title{
Resolving future fire management conflicts using multi-criteria decision making
}

\author{
Abstract \\ Management strategies to reduce the risks to human life and property from wildfire \\ commonly involve burning native vegetation. However, planned burning can conflict with \\ other societal objectives such as human health and biodiversity conservation. These conflicts \\ are likely to intensify as fire regimes change under future climates and as growing human \\ populations encroach further into fire-prone ecosystems. Decisions about managing fire risks \\ are therefore complex and warrant more sophisticated approaches than are usually applied. \\ We demonstrate a multi-criteria decision making approach (MCDA) with potential to \\ improve fire management outcomes. For a case study from a highly populated, biodiverse \\ and flammable wildland-urban interface, we considered the effects of 22 planned burning \\ options on eight objectives: house protection, water quality, carbon emissions/human health, \\ and five distinct species types. MCDA identified a small number of management options \\ (burning forest adjacent to houses) that performed well for most objectives, but not for one \\ species-type (arboreal mammal) and water-quality. While MCDA made this conflict explicit, \\ resolution of the problem depended on the weighting assigned to each objective. Additive \\ weighting of criteria sacrificed the arboreal mammal and water quality for gains in other \\ objectives. Multiplicative weighting identified scenarios that avoided poor outcomes for any \\ objective; important for avoiding potentially irreversible biodiversity losses. To distinguish \\ reliably among management options, future work should focus on reducing uncertainty in \\ outcomes across a range of objectives. Considering management actions that have more \\ predictable outcomes than landscape fuel management will be important. Our study \\ demonstrates that, where data are adequate, MCDA can support decision-making in the \\ complex and often conflicted area of fire management.
}




\section{Introduction}

Fire management is an interaction with natural landscapes and human populations on a multibillion dollar scale (Calkin et al. 2014; Stockmann et al. 2010). Across the globe, fire management is a major budget item for governments, community organisations and individuals, and these costs are rising (Calkin et al. 2014; Gude et al. 2008). Costs of wildfire management in the USA, for example, are in the order of $\$ 3$ billion every year, plus substantially more in property losses and fuel management (Calkin et al. 2014; GAO 2009; Stockmann et al. 2010). As the global climate changes, fires are expected to become larger and more frequent in many ecosystems and on most continents (King et al. 2013; Stephens et al. 2013). Human populations continue to grow and urbanise, expanding the interface between high-density urban centres and fire-prone lands, and hence increasing the exposure of humans and their assets to wildfire threats (Hammer et al. 2009). These trends demand increased preparedness, along with increased management intervention (Flannigan et al. 2009) or more cost-effective management strategies (Stockmann et al. 2010).

These global changes pose major problems to land management agencies facing choices for the most effective ways to mitigate risk of fire impacts on human lives and property, while taking into account the costs and impacts on a range of societal values (Driscoll et al. 2010; Ohlson et al. 2006). A solution to this problem must confront major complexities in decisionmaking (Calkin et al. 2014). For example, the cost of fire prevention actions can be an order of magnitude more than the value of the assets that are likely to be protected (Penman et al. 2011a; Stockmann et al. 2010). Planned burning can increase (Bradstock et al. 2012a; Vilen \& Fernandes 2011) or decrease (Heckbert et al. 2012) greenhouse gas emissions, and can help protect water quality (Smith et al. 2011). Smoke from landscape fires has major health effects globally, killing between 260,000 and 600,000 people each year (Johnston et al. 2012) 
and is released from fires in proportion to the amount of fuel consumed and area burned (Ward \& Hardy 1991). Further conflicts exist in using fire to protect biodiversity compared with houses and human lives (DellaSala et al. 2004; Driscoll et al. 2010). Many fire-prone ecosystems are highly biodiverse, and co-exist alongside dense human populations (Keeley et al. 2011). Depending on how it is implemented, planned fire may negatively affect some species (DellaSala et al. 2004), while other species may benefit (Fontaine \& Kennedy 2012).

Given that fire management has impacts on a broad range of societal values, explicit evaluation of the trade-offs and co-benefits of different fire management actions should help to resolve the often acrimonious debate around fire management (Calkin et al. 2014; DellaSala et al. 2004; Driscoll et al. 2010; Haslem et al. 2011). Multi-criteria decision analysis (MCDA) has the potential to identify solutions to fire management that minimise conflicts between objectives (Driscoll et al. 2010; Kennedy \& Ford 2011). Decisions in environmental sciences are often challenged by social, environmental and economic tradeoffs. Resolving these imperatives has generated substantial growth in the application of MCDA in environment-related fields (Huang et al. 2011). However, these advanced techniques are under-utilized for resolving complex multiple-objective decisions in fire management. Of the few studies that apply decision theory to fire management, most examine one or two fire management objectives including combinations of biodiversity conservation, risk, or cost (Ager et al. 2010; Breininger et al. 2014; Johnson et al. 2011; Kennedy et al. 2008; McCarthy et al. 2001; Richards et al. 1999). Other studies aim to identify priority areas for fire treatment (Reynolds \& Hessburg 2005), and only two evaluate fire management scenarios based on multiple objectives and treatment costs (Ohlson et al. 2006; Shang et al. 2011). 
In this paper, we concurrently address eight contrasting fire management objectives: protecting houses from wildfire; maintaining high water quality; minimizing carbon emissions/health effects and conserving five species types. Our aim is to explicitly examine the trade-offs and co-benefits of 22 alternative management scenarios for achieving the eight objectives. We ask: can decision theory simplify the complex task of choosing between large numbers of fire management interventions that will simultaneously impact on a range of important but competing objectives?

We address this question by applying three different MCDA tools to a case-study of fire management in a highly populated, biodiverse and flammable landscape. Instead of using habitat surrogates as a biodiversity response, we estimate the response of biodiversity to fire directly by simulating changes in abundance of five species types, each differently affected by fire regimes. Our approach also allows us to compare a large number of spatially-realistic management alternatives. It therefore opens the door for management agencies to explore the merits of a wide range of novel and traditional management options for achieving multiple objectives in landscapes where humans choose to live amidst flammable ecosystems.

\section{Methods}

We used the fire simulations of Bradstock et al. (2012b) to quantify the response of fire regimes to differing management scenarios of prescribed burning in the Blue Mountains region near Sydney, Australia (Fig. 1). Dry sclerophyll forest with shrubby understory covers $75 \%$ of the study region, with the remainder consisting of heathlands, wet sclerophyll forest, rainforest and grassy woodlands (Bradstock et al. 2012b). Combinations of crown and understory-only fires are typical of the region (Bradstock et al. 2010). 
The model was used to simulate the response of fire regimes to 22 prescribed fire scenarios. The scenarios included five levels of burning effort $(0,4,8,12,16$, and $20 \%$ of the area available for burning according to the spatial burn plan), four spatial burn plans (edge, unconstrained, constrained, and linear; Fig. 1, see Fig. 4 in Results for tabulation of each management scenario), plus a scenario with no prescribed burning, and one representing current burning practices (constrained, 0.75\%). The fire simulation used FIRESCAPE which modelled spatially explicit fires taking into account weather, terrain and fuel dynamics (Bradstock et al. 2012b; Cary et al. 2009). The model was based on a chronology of recent daily weather for the region (hourly records, 1977 to 2003), repeated 50 times. Stochasticity in ignitions was simulated from probabilistic functions for lightning and human ignitions (Bradstock et al. 2012b). We extracted fire intensity and maximum Forest Fire Danger Index (FFDI) from these simulations for a subsample of grid cells $(100 \times 100 \mathrm{~m}$ size $)$ spaced evenly at $500 \mathrm{~m}$ intervals. These protocols were repeated 50 times, giving 50 fire sequences. The model was able to reproduce the fire size distribution from fire history data and simulated prescribed burning reduced subsequent wildfire size to an extent consistent with empirical data (Bradstock et al. 2012b).

We subsequently estimated the consequence of the sequences of simulated fires for eight management objectives (details in Appendix S1): (1) minimising house loss, where house loss was a function of fire intensity in cells adjacent to houses; (2) minimising carbon emissions/health effects, a function of fire intensity and FFDI; (3) minimising the impact of fire-related soil erosion on catchment water quality, a function of area burnt within a water catchment; and (4-8) maximising the population extent of five species types representing qualitatively different species responses to fire regimes. The species included a shrub (Hakea constablei), a grass tree (Xanthorrhoea resinosa), an arboreal marsupial glider (Petaurus 
volans), a frog (Heleioporus australiacus) and a lizard (Pseudemoia entrecasteauxii).

Predicted population size responses to fire were derived from stage-structured matrix models, parameterised for high and low intensity fire (Table S1, Fig. S1).

We used three approaches to considering the trade-offs among objectives provided by the 22 alternative fire management scenarios.

\section{Pareto surfaces}

We first generated pair-wise Pareto surfaces (Chankong \& Haimes 1983). The axis for each objective was scaled from zero to one indicating least desirable to most desirable outcome observed. The mean outcome of 50 replicate simulations for the different management scenarios are therefore plotted in two dimensional space for each pair-wise comparison (Driscoll et al. 2010). A sub-optimal (dominated) management scenario is below and to the left of at least one other scenario in the Pareto surface. The Pareto frontier is formed by linking management scenarios that are not sub-optimal (known as "non-dominated" decisions), describing an arc from the top left to the bottom right of the performance space, making any trade-offs explicit. We also consider all eight axis to assess whether any of the scenarios were non-dominated along all dimensions simultaneously.

\section{Robust decision-making}

We use multi-attribute utility theory to combine the eight objectives into a single aggregate objective, using either additive or multiplicative operations (Guitouni \& Martel 1998). The weighting that should be assigned to each separate objective in the utility function is often unclear because objectives are measured using incompatible units, and stakeholders derive different amounts of utility from each objective. 
One solution is to search for management scenarios that are robust to a wide range of weightings. We first use additive utility functions that are linear with respect to the different objectives, and are characterised by a set of weightings that vary between 0 and 1 (i.e., from objectives with no value to those that are maximally important). Objectives therefore contribute independently to utility.

Mathematically, the additive utility that stakeholder $i$ derives from a management scenario $s$ is denoted $U_{i s}^{A}$. This utility is based on the mean outcome for each objective $j$ that result from an implementation of management scenario $s: x_{j s}$. The coefficients $v_{i j}$ indicate the weight assigned by stakeholder $i$ to objective $j$.

$$
U_{i s}^{A}=\sum_{j=1}^{J} v_{i j} x_{j s},
$$

To identify management strategies that were robust to different weightings placed on objectives, we determined which management strategies could most consistently provide satisfactory outcomes when objective utility weights varied across a wide range of values. We selected random values from a uniform distribution for each weighting $\left(v_{i j} \sim\right.$ Uniform[0,1], for $\left.i=1: 10,000\right)$. With the outcomes for each of these 10,000 simulated weightings, we calculated the subset of management decisions that would provide satisfactory utility (when a management scenario provided more than $95 \%$ of the maximum outcome observed for that objective). For this large number of alternative weightings, we constructed frequency distributions for the proportion of stakeholders who would be satisfied by each of the fire management scenarios. 
In additive utility functions, low scores from one objective in the utility function can be offset by high scores in others. In contrast, using multiplicative functions, a zero value for any one objective cannot be overwhelmed by larger values for other objectives. We repeated the robust decision-making approach described above, but applied a multiplicative function based on the Cobb-Douglas formula (Houthakker 1955):

$$
U_{i}^{M}=\prod_{j=1}^{J} x_{j}^{v_{i j}},
$$

\section{Mutually acceptable outcomes}

In some situations, decision-makers can be satisfied by a management strategy that improves outcomes for at least one objective compared to the current management strategy, provided it does not lead to worse outcomes for other objectives. For the Blue Mountains fire management problem, we constructed "consequence tables" that classify management actions according to whether or not they increase or decrease the outcome for each objective by $10 \%$ or more compared with current management.

\section{Results}

Pareto surfaces

The eight different objectives (house protection, carbon/health, water quality, five species types) generated 28 pairwise comparisons (Fig. S2). When Pareto efficiency was considered for all eight management objectives simultaneously, all of the scenarios were non-dominated. That is, every scenario was among the non-dominated set of scenarios for at least one of the pair-wise comparisons. 
For the comparisons of house-protection with other objectives, we observed positive relationships between house protection, and three other objectives (water quality, glider, frog, Fig. 2). In these cases, one or a small number of solutions performed well for both of the objectives that were compared. Negative relationships existed between house protection and carbon/health effects, the shrub, grass-tree and lizard. Management scenarios involving very high levels of planned burning increased house protection, but reduced shrub, grass-tree and lizard populations, while increasing carbon emissions and adverse health impacts.

Compromise solutions that aim for at least moderate performance in all objectives occur near the mid-point of each Pareto frontier. Strategies that focussed on burning forest adjacent to the urban interface (edge treatment) were on the mid-points of Pareto frontiers when comparing house protection against carbon/health, the shrub, grasstree and lizard (Fig. 2). For house protection, edge burns performed as well as randomly burning $16 \%$ of the landscape but required less total area to be burnt (1.3-1.7\%, Fig. 2). Only the glider performed poorly when the landscape was managed with edge burns (Fig. 2c). Current management was always a suboptimal solution when considering house protection against other objectives.

\section{Robust decision-making}

Using the additive utility function, two of the 22 management scenarios were able to deliver near-optimal outcomes, across a wide range of possible priorities among objectives. That is, these two scenarios led to a total utility of $\geq 95 \%$ of optimal for $>60 \%$ of weightings. The robust decisions included two of the five edge scenarios (Fig. 3a). With a multiplicative

utility function, two different scenarios were near-optimal for $>60 \%$ of weightings (scenario 8 , unconstrained $4 \%$, and scenario 17 , constrained $20 \%$, Fig. 3 b). 


\section{Mutually acceptable outcomes}

None of the planned burning scenarios that we considered improved outcomes for all objectives. In every case, at least one objective was worse off compared with current management (Fig. 4). For example, three strategies (edge 4\%, edge 8\%, constrained 4\%) led to improvements in outcomes for the shrub, grass-tree, frog, lizard, carbon/human health and house protection, but a decrease in performance for gliders and water quality.

\section{Discussion}

Fire management decisions are frequently based on achieving a single objective of protecting houses or maintaining forest production, and therefore do not take into account the full social, environmental and economic consequences of fire management. Further, such approaches sometimes do not consider how effective fire management is for achieving their stated objective (DellaSala et al. 2004; Driscoll et al. 2010). These omissions are becoming increasingly problematic as climate change drives more severe fire weather (Mouillot et al. 2002) and human population growth contributes to expand the wildland-urban interface (Hammer et al. 2009). Our study shows that it is feasible to simultaneously consider a broad range of scenarios in fire management and to find a small number of solutions that minimise conflict and make any remaining necessary trade-offs explicit..

\section{Simplifying the complex decision task}

Although we examined 22 management scenarios, each multi-criteria method highlighted a small number of options that represented different compromises among management objectives. Pareto surfaces, the additive robust method and mutually acceptable outcomes all highlighted edge burning as an optimal approach among the 22 management options, providing increased performance in house protection and five of the other seven objectives. 
Empirical and simulation studies show that fuel treatments adjacent to houses has a dominant influence over the risk of house loss in wildfires compared with more distant fuel management approaches (Ager et al. 2010; Gibbons et al. 2012; Penman et al. 2014; Price \& Bradstock 2012; Syphard et al. 2014). Focussing fuel treatments close to houses is likely to benefit some species by allowing more high intensity fire in the landscape and reducing the total area that is burnt (Fig. S1c-e). However, if fuel treatments are only applied near to houses, there may be trade-offs for other species that are vulnerable to high intensity fire (Fig. S1a, Ager et al. 2010)..

Pareto surfaces were critical for highlighting and interpreting the compromises identified by the robust decision-making approach (also see Kennedy et al. 2008). Our additive function, where the performance against each objective was summed, suggested that edge-burning was the best performing scenario. Reference to the Pareto surfaces show that the edge scenarios perform well for most objectives, but poorly for the glider and water quality. An additive approach may therefore be disastrous in a conservation context where the focus is on avoiding poor outcomes for any species, rather than maximising the average outcome across species. In contrast, the multiplicative function, where performance against each objective was multiplied, indicated that edge-burning was rarely among the best management options. We suggest that a multiplicative function is most appropriate in situations where extremely poor performance of one objective cannot be compensated by good performance of other objectives. Alternatively, different multi-criteria aggregation procedures could be used, such as the conjunctive method which sets minimal acceptable criteria for each objective (Guitouni \& Martel 1998). 
Considering a broader range of management options could simplify the decision task by changing the shape of Pareto frontiers and helping to identify management options that are dominated across all objectives. For example, if the risk of houses burning could be reduced by $50 \%$, then the slope of the trade-offs between house protection and other conflicting objectives would be proportionally reduced (Fig. S3). The impact of intense fires on houses can be reduced by vegetation management (Gibbons et al. 2012), improved building design and materials (Stephens et al. 2009), and defence during the blaze (Whittaker et al. 2013). When different objectives are mutually exclusive, changing the shape of trade-offs by considering new management strategies has the potential to defuse wicked problems (in an engineering context see Zechman et al. 2013). Multi-criteria decision analysis therefore can help cut through the cultural inertia that is often associated with forest management (Carrillo \& Gromb 2007; Fernandes et al. 2013; Kennedy \& Quigley 1998). Rather than maintaining the predominant culture of either limited burning (Fernandes et al. 2013) or widely burning, using decision-theory, the benefits of alternative management approaches can be clearly evaluated (Fig. S3).

The challenge now is to further explore different management options. In addition to alternative approaches to protecting houses, fire management strategies associated with urban planning (Syphard et al. 2013), and rapid response when fires begin (Penman et al. 2011b) could reduce the fire risk. Our analyses used a limited number of spatially explicit burning scenarios. However, more sophisticated spatial management can already be implemented (van Wilgen et al. 2014). To better align simulations with plausible management interventions, the model could, for example, tailor burning practices to the distribution of species, the location of water catchments, or the current fire history. Prioritising different 
objectives in different areas may also contribute to resolving landscape-wide conflicts among objectives.

\section{Weightings}

We assumed that objectives could be assigned a full range of weightings (robust method), or are considered without weightings (mutually acceptable outcomes, Pareto surfaces with standardized axis) because our performance criteria gave relative values. For example, as a surrogate for degradation of water quality we used the area of the catchment near water storages that were burnt at high intensity. While fires can degrade water quality (Smith et al. 2011), the extent of degradation for a given area that is burnt is unknown, and likely to vary with terrain and soil type. Therefore it is difficult to place meaningful weights on water quality outcomes because we do not know how severe (or expensive) changes in water quality are across the range of management scenarios.

Our species simulations may also be difficult to interpret, even though they provided a response on a demographically meaningful scale. The species types were based on data rich examples, four of which had been previously published as population viability analyses. Nonetheless, despite parameterization of the models based on up to 20 years of demographic data, there remain uncertainties in some aspects of their fire responses. Fortunately, although simulation models do not generally provide reliable absolute predictions of extinction risk, they can still offer robust rankings of alternative actions (McCarthy et al. 2003).

When performance criteria have an undefined scale, meaningful weights cannot be assigned to individual objectives. The robust method is therefore a critical tool because it identifies scenarios that perform well across the full range of weightings. A robust approach to 
weighting will be needed in cases where research to define the absolute values of performance measures cannot be funded.

\section{Progressing towards application}

Future work should explore how management rankings change with more sophisticated indicators of performance. For example, an improved model could consider water catchment impacts of roads associated with fire management (Christie et al. 2013), carbon sequestration by plant growth (Murphy et al. 2010), and a finer grained landscape enabling effects of vegetation within 5-40 m of houses to be accounted for (Gibbons et al. 2012; Syphard et al. 2014).. Our population models represent a more diverse and proximal evaluation of biodiversity outcomes than more generalised biodiversity indices (Ohlson et al. 2006). Nevertheless, our five species types represent a sample of biodiversity, and exploring how rankings change with additional species types would be valuable. More realistic fire simulation scenarios are also an important area for future research. Increased planned burning comes with an increased risk of escaped fires (Brunson \& Evans 2005), and of high intensity fire, but these risks were not included in our fire simulations. If these risks were included, the beneficial effects of extensive planned burning for water quality and gliders would be reduced, decreasing the apparent conflict between these objectives and most others.

Feasibility and cost of management scenarios also warrant further development (Penman et al. 2011a). The scenario favoured by the multiplicative robust analysis ( $4 \%$ unconstrained planned burning) represents more than five times the amount of planned burning currently undertaken in the study area $(0.75 \%)$, a level of burning that exceeds likely changes to funding availability (Penman et al. 2011a). Costs of management could be incorporated by either considering the total management cost as another dimension in the objective function 
(Penman et al. 2014), or by calculating the efficiency of the existing objectives (i.e., outcomes per-unit dollar), rather than their absolute magnitude.

Our aim was to illustrate a decision-making approach to fire management. However, to implement our suggested approach effectively, uncertainty in estimated responses to management must be explicitly considered. For example, we repeated our analyses to take into account uncertainty from 50 simulated fire runs, rather than using the mean value. We found that most management scenarios could not be distinguished (Fig. S4), the range of robust solutions was much broader and each solution was optimal less often (Fig. S5), and few management scenarios led to a $10 \%$ better or worse outcome compared with current management (Fig. S6). This uncertainty suggests that the vagaries of ignition location and weather conditions in our simulation make the effect of planned burning on a range of objectives unpredictable. A focus on management that could have more certain outcomes is therefore a research priority, including research into managing the home ignition zone (Calkin et al. 2014), and managing other threats to species that might offset the effects of suboptimal fire regimes (Bonebrake et al. 2014).

In addition to uncertainty around fire simulations, we have not considered uncertainty or stochasticity associated with predicting fire responses for each objective which also needs to be accommodated in future work.

\section{Conclusions}

Multi-criteria decision analysis can be used to help cut through cultural inertia (Carrillo \& Gromb 2007; Fernandes et al. 2013; Kennedy \& Quigley 1998) so that fire management can perform better against a range of objectives. Multiplicative robust methods are preferred 
when an important goal is to avoid poor performance of any objective. Reducing uncertainty in model outcomes remains an important challenge, and a key approach to address this will be to consider alternative management approaches that have less inherent uncertainty in outcome compared with landscape fuel treatments. With further development of the methods we apply here, management agencies in fire-prone countries around the world may find new, more effective, and less controversial approaches of better managing increasing fire risks at the expanding wildland-urban interface.

\section{Supporting Information}

Appendix S1, Table S1, and Fig.s S1-6 are available online. The authors are solely responsible for the content and functionality of these materials. Queries (other than absence of the material) should be directed to the corresponding author.

\section{Literature Cited}

Ager, A. A., N. M. Valliant, and M. A. Finney. 2010. A comparison of landscape fuel treatment strategies to mitigate wildland fire risk in the urban interface and preserve old forest structure. Forest Ecology and Management 259:1556-1570.

Bonebrake, T. C., A. D. Syphard, J. Franklin, K. E. Anderson, H. R. AkÇAkaya, T. Mizerek, C. Winchell, and H. M. Regan. 2014. Fire Management, Managed Relocation, and Land Conservation Options for Long-Lived Obligate Seeding Plants under Global Changes in Climate, Urbanization, and Fire Regime. Conservation Biology early online DOI: 10.1111/cobi.12253.

Bradstock, R. A., M. M. Boer, G. J. Cary, O. F. Price, R. J. Williams, D. Barrett, G. Cook, A. M. Gill, L. B. W. Hutley, H. Keith, S. W. Maier, M. Meyer, S. H. Roxburgh, and J. 
Russell-Smith. 2012a. Modelling the potential for prescribed burning to mitigate carbon emissions from wildfires in fire-prone forests of Australia. International Journal of Wildland Fire 21:629-639.

Bradstock, R. A., G. J. Cary, I. Davies, D. B. Lindenmayer, O. F. Price, and R. J. Williams. 2012b. Wildfires, fuel treatment and risk mitigation in Australian eucalypt forests: Insights from landscape-scale simulation. Journal of Environmental Management 105:66-75

Bradstock, R. A., K. A. Hammill, L. Collins, and O. Price. 2010. Effects of weather, fuel and terrain on fire severity in topographically diverse landscapes of south-eastern Australia. Landscape Ecology 25:607-619.

Breininger, D., B. Duncan, M. Eaton, F. Johnson, and J. Nichols. 2014. Integrating Land Cover Modeling and Adaptive Management to Conserve Endangered Species and Reduce Catastrophic Fire Risk. Land 3:874-897.

Brunson, M. W., and J. Evans. 2005. Badly burned? Effects of an escaped prescribed burn on social acceptability of wildland fuels treatments. Journal of Forestry 103:134-138.

Calkin, D. E., J. D. Cohen, M. A. Finney, and M. P. Thompson. 2014. How risk management can prevent future wildfire disasters in the wildland-urban interface. Proceedings of the National Academy of Sciences 111:746-751.

Carrillo, J. D., and D. Gromb. 2007. Cultural inertia and uniformity in organizations. Journal of Law Economics \& Organization 23:743-771.

Cary, G., M. Flannigan, R. Keane, R. Bradstock, I. Davies, J. Lenihan, C. Li, K. Logan, and R. Parson. 2009. Relative importance of fuel management, ignition management and weather for area burned: evidence from five landscape-fire-succession models. International Journal of Wildland Fire 18:147-156. 
Chankong, V., and Y. Haimes 1983. Multiobjective Decision Making Theory and Methodology. North-Holland, New York, NY.

Christie, A. M., W. M. Aust, S. M. Zedaker, and B. D. Strahm. 2013. Potential Erosion from Bladed Fire lines in the Appalachian Region Estimated with USLE-Forest and WEPP Models. Southern Journal of Applied Forestry 37:140-147.

DellaSala, D. A., J. E. Williams, C. D. Williams, and J. E. Franklin. 2004. Beyond smoke and mirrors: a synthesis of fire policy and science. Conservation Biology 18:976-986.

Driscoll, D. A., D. B. Lindenmayer, A. F. Bennett, M. Bode, R. A. Bradstock, G. J. Cary, M. F. Clarke, N. Dexter, R. Fensham, G. Friend, M. Gill, S. James, G. Kay, D. A. Keith, C. MacGregor, H. P. Possingham, J. Russel-Smith, D. Salt, J. E. M. Watson, R. J. Williams, and A. York. 2010. Resolving conflicts in fire management using decision theory; asset-protection versus biodiversity conservation. Conservation Letters 3:215223.

Fernandes, P. M., G. M. Davies, D. Ascoli, C. Fernandez, F. Moreira, E. Rigolot, C. R. Stoof, J. A. Vega, and D. Molina. 2013. Prescribed burning in southern Europe: developing fire management in a dynamic landscape. Frontiers in Ecology and the Environment 11:E4-E14.

Flannigan, M., B. Stocks, M. Turetsky, and M. Wotton. 2009. Impacts of climate change on fire activity and fire management in the circumboreal forest. Global Change Biology 15:549-560.

Fontaine, J. B., and P. L. Kennedy. 2012. Meta-analysis of avian and small-mammal response to fire severity and fire surrogate treatments in U.S. fire-prone forests. Ecological Applications 22:1547-1561.

GAO 2009. Wildland fire management. United States Government Accountability Office, Washington DC. 
Gibbons, P., L. van Bommel, A. M. Gill, G. J. Cary, D. A. Driscoll, R. A. Bradstock, E. Knight, M. A. Moritz, S. L. Stephens, and D. B. Lindenmayer. 2012. Land Management Practices Associated with House Loss in Wildfires. Plos One 7:e29212. Gude, P., R. Rasker, and J. van den Noort. 2008. Potential for Future Development on FireProne Lands. Journal of Forestry 106:198-205.

Guitouni, A., and J.-M. Martel. 1998. Tentative guidelines to help choosing an appropriate MCDA method. European Journal of Operational Research 109:501-521.

Hammer, R. B., S. I. Stewart, and V. C. Radeloff. 2009. Demographic Trends, the WildlandUrban Interface, and Wildfire Management. Society \& Natural Resources 22:777-782. Haslem, A., L. T. Kelly, D. G. Nimmo, S. J. Watson, S. A. Kenny, R. S. Taylor, S. C. Avitabile, K. E. Callister, L. M. Spence-Bailey, M. F. Clarke, and A. F. Bennett. 2011. Habitat or fuel? Implications of long-term, post-fire dynamics for the development of key resources for fauna and fire. Journal of Applied Ecology 48:247256.

Heckbert, S., J. Russell-Smith, A. Reeson, J. Davies, G. James, and C. Meyer. 2012. Spatially explicit benefit-cost analysis of fire management for greenhouse gas abatement. Austral Ecology 37:724-732.

Houthakker, H. S. 1955. The Pareto Distribution and the Cobb-Douglas Production Function in Activity Analysis. The Review of Economic Studies 23:27-31.

Huang, I. B., J. Keisler, and I. Linkov. 2011. Multi-criteria decision analysis in environmental sciences: Ten years of applications and trends. Science of the Total Environment 409:3578-3594.

Johnson, F. A., D. R. Breininger, B. W. Duncan, J. D. Nichols, M. C. Runge, and B. K. Williams. 2011. A Markov Decision Process for Managing Habitat for Florida ScrubJays. Journal of Fish and Wildlife Management 2:234-246. 
Johnston, F. H., S. B. Henderson, Y. Chen, J. T. Randerson, M. Marlier, R. S. DeFries, P. Kinney, D. M. J. S. Bowman, and M. Brauer. 2012. Estimated Global Mortality Attributable to Smoke from Landscape Fires. Environmental Health Perspectives 120:695-701.

Keeley, J. E., W. J. Bond, R. A. Bradstock, J. G. Pausas, and P. W. Rundel 2011. Fire in Mediterranean Ecosystems. Cambridge University Press, London.

Kennedy, J. J., and T. M. Quigley. 1998. Evolution of USDA Forest Service organizational culture and adaptation issues in embracing an ecosystem management paradigm. Landscape and Urban Planning 40:113-122.

Kennedy, M. C., and E. D. Ford. 2011. Using Multicriteria Analysis of Simulation Models to Understand Complex Biological Systems. Bioscience 61:994-1004.

Kennedy, M. C., E. D. Ford, P. Singleton, M. Finney, and J. K. Agee. 2008. Informed multiobjective decision-making in environmental management using Pareto optimality. Journal of Applied Ecology 45:181-192.

King, K. J., G. J. Cary, R. A. Bradstock, and J. B. Marsden-Smedley. 2013. Contrasting fire responses to climate and management: insights from two Australian ecosystems. Global Change Biology 19:1223-1235.

McCarthy, M. A., S. J. Andelman, and H. P. Possingham. 2003. Reliability of relative predictions in population viability analysis. Conservation Biology 17:982-989.

McCarthy, M. A., H. P. Possingham, and A. M. Gill. 2001. Using stochastic dynamic programming to determine optimal fire management for Banksia ornata. Journal of Applied Ecology 38:585-592.

Mouillot, F., S. Rambal, and R. Joffre. 2002. Simulating climate change impacts on fire frequency and vegetation dynamics in a Mediterranean-type ecosystem. Global Change Biology 8:423-437. 
Murphy, B. P., J. Russell-Smith, and L. D. Prior. 2010. Frequent fires reduce tree growth in northern Australian savannas: implications for tree demography and carbon sequestration. Global Change Biology 16:331-343.

Ohlson, D. W., T. M. Berry, R. W. Gray, B. A. Blackwell, and B. C. Hawkes. 2006. Multiattribute evaluation of landscape-level fuel management to reduce wildfire risk. Forest Policy and Economics 8:824-837.

Penman, T. D., R. A. Bradstock, and O. F. Price. 2014. Reducing wildfire risk to urban developments: Simulation of cost-effective fuel treatment solutions in south eastern Australia. Environmental Modelling \& Software 52:166-175.

Penman, T. D., F. J. Christie, A. N. Andersen, R. A. Bradstock, G. J. Cary, M. K. Henderson, O. Price, C. Tran, G. M. Wardle, R. J. Williams, and A. York. 2011a. Prescribed burning: how can it work to conserve the things we value? International Journal of Wildland Fire 20:721-733.

Penman, T. D., O. Price, and R. A. Bradstock. 2011b. Bayes Nets as a method for analysing the influence of management actions in fire planning. International Journal of Wildland Fire 20:909-920.

Price, O. F., and R. A. Bradstock. 2012. The efficacy of fuel treatment in mitigating property loss during wildfires: Insights from analysis of the severity of the catastrophic fires in 2009 in Victoria, Australia. Journal of Environmental Management 113:146-157.

Reynolds, K. M., and P. F. Hessburg. 2005. Decision support for integrated landscape evaluation and restoration planning. Forest Ecology and Management 207:263-278.

Richards, S. A., H. P. Possingham, and J. Tizard. 1999. Optimal fire management for maintaining community diversity. Ecological Applications 9:880-892. 
Shang, Z., H. S. He, W. Xi, S. R. Shifley, and B. J. Palik. 2011. Integrating LANDIS model and a multi-criteria decision-making approach to evaluate cumulative effects of forest management in the Missouri Ozarks, USA. Ecological Modelling 229:50-63.

Smith, H. G., G. J. Sheridan, P. N. J. Lane, P. Nyman, and S. Haydon. 2011. Wildfire effects on water quality in forest catchments: A review with implications for water supply. Journal of Hydrology 396:170-192.

Stephens, S. L., M. A. Adams, J. Handmer, F. R. Kearns, B. Leicester, J. Leonard, and M. A. Moritz. 2009. Urban-wildland fires: how California and other regions of the US can learn from Australia. Environmental Research Letters 4.

Stephens, S. L., J. K. Agee, P. Z. Fulé, M. P. North, W. H. Romme, T. W. Swetnam, and M. G. Turner. 2013. Managing Forests and Fire in Changing Climates. Science 342:4142.

Stockmann, K., J. Burchfield, D. Calkin, and T. Venn. 2010. Guiding preventative wildland fire mitigation policy and decisions with an economic modeling system. Forest Policy and Economics 12:147-154.

Syphard, A. D., A. Bar Massada, V. Butsic, and J. E. Keeley. 2013. Land Use Planning and Wildfire: Development Policies Influence Future Probability of Housing Loss. Plos One 8.

Syphard, A. D., T. J. Brennan, and J. E. Keeley. 2014. The role of defensible space for residential structure protection during wildfires. International Journal of Wildland Fire 23:1165-1175.

van Wilgen, B. W., N. Govender, I. P. J. Smit, and S. MacFadyen. 2014. The ongoing development of a pragmatic and adaptive fire management policy in a large African savanna protected area. Journal of Environmental Management 132:358-368. 
Vilen, T., and P. M. Fernandes. 2011. Forest Fires in Mediterranean Countries: $\mathrm{CO}(2)$ Emissions and Mitigation Possibilities Through Prescribed Burning. Environmental Management 48:558-567.

Ward, D. E., and C. C. Hardy. 1991. Smoke emissions from wildland fires. Environment International 17:117-134.

Whittaker, J., K. Haynes, J. Handmer, and J. McLennan. 2013. Community safety during the 2009 Australian 'Black Saturday' bushfires: an analysis of household preparedness and response. International Journal of Wildland Fire 22:841-849.

Zechman, E. M., M. H. Giacomoni, and M. E. Shafiee. 2013. An evolutionary algorithm approach to generate distinct sets of non-dominated solutions for wicked problems. Engineering Applications of Artificial Intelligence 26:1442-1457. 
Fig. 1. The Blue Mountains study area showing the burn blocks and the study area in eastern Australia. Planned burns were simulated to occur within forest blocks that were either adjacent to the edge (blue) of the urban area (peach), in 'linear' arrangements across the landscape (orange), or unconstrained (yellow, orange and blue forest blocks).

Fig. 2. Pareto surfaces comparing house protection with seven other objectives. Management scenarios on the Pareto frontier are circled, where the Pareto frontier is defined by the management strategies for which no other strategies have better performance for both objectives in the comparison. Colours indicate the burn scenario (black = no burn; dark blue $=$ edge; green $=$ unconstrained; pink $=$ constrained; light blue $=$ linear; pink cross $=$ current management). Circle radius represents the percentage of study area burnt. Axes are scaled from 0 (worst performing scenario) to 1 (best performing scenario). Thus: Carbon/Health $=$ Reduction in emissions; House protection = Reduction in house losses; Animal and plant species types $=$ Change in regional distribution relative to initial distribution .

Fig. 3. Robust decision making analysis indicating the robustness of management actions to variation in weighting of the utility function, based on (a) additive functions and (b) multiplicative functions. Bars indicate the relative frequency with which management scenarios (x-axis, numbered S1 to S22 from left to right, see Fig. 4) yielded near-optimal outcomes (within 5\% of maximal) according to randomly chosen weightings for the utility functions. Percentages indicate area of total landscape burnt (rather than the percentage treated of the blocks available, see Fig. 4). Scenarios are labelled by the percentage of the region prescribed burned. Pink: constrained; black: no burning; dark blue: edge; green: unconstrained; light blue: linear. 
Fig. 4. Mutually acceptable outcomes for 22 prescribed burning scenarios (rows), according to a set of eight objectives (columns). Management scenarios improve (dark green), reduce (orange), or have no effect on (white) the utility function, compared with the current management scenario (scenario 1). Improvements or reductions are more than $10 \%$ different from current performance. Burning strategies: Edge (treatment of urban edge blocks only); Unconstrained (random selection of blocks irrespective of proximity to the urban interface); Constrained (selection of 'edge' and non-edge blocks on an evenly weighted basis) and; Linear (arrays of blocks arranged in intersecting north-south and east-west linear segments). Burning effort is the annual area treated as a percentage of the area of blocks available for burning according to the burning scenario. Burning area is this area as a percentage of the Blue Mountains study region. $\mathrm{C} /$ health $=$ Carbon $/$ Health . 


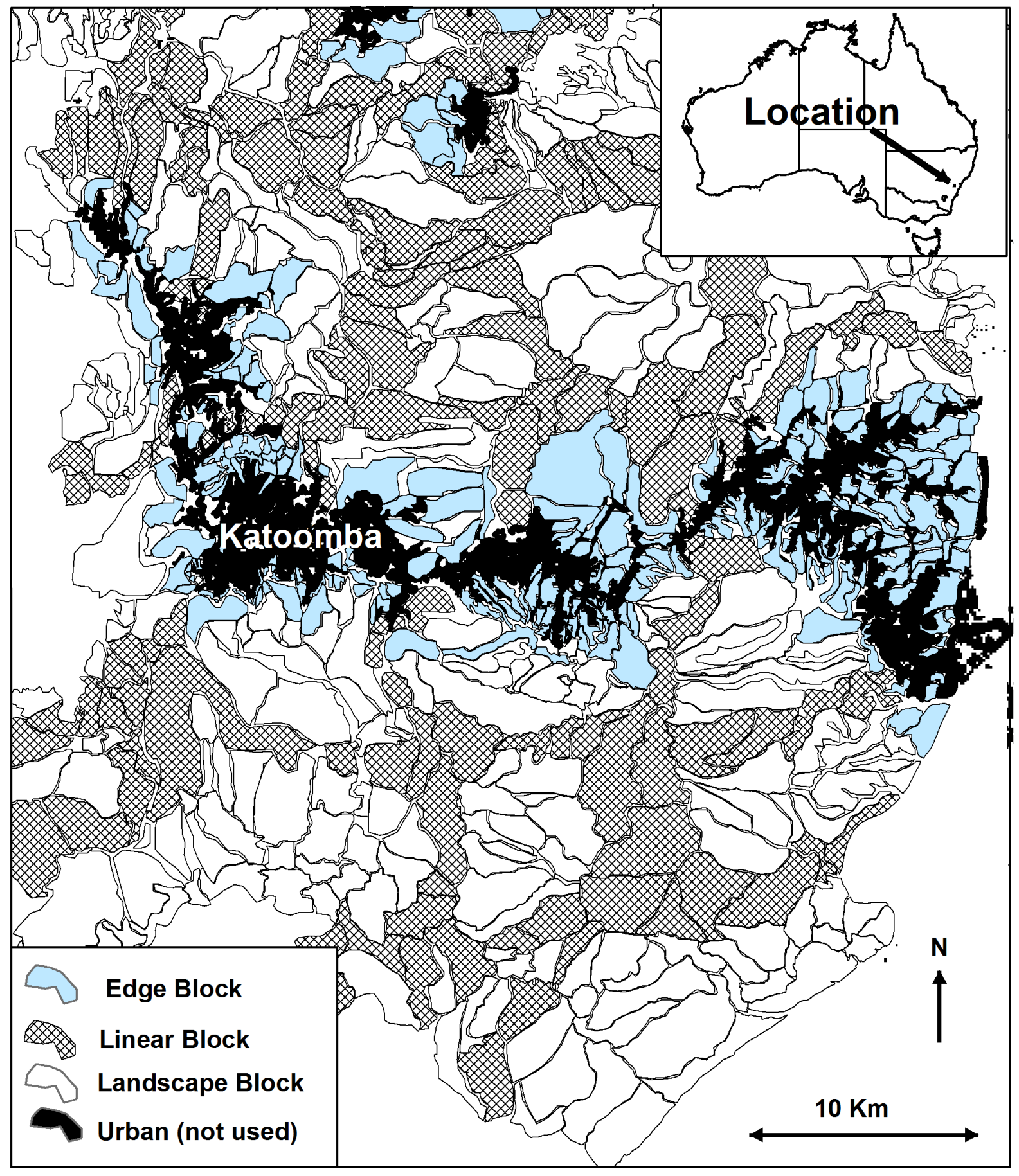

Fig. 1. 
(a)

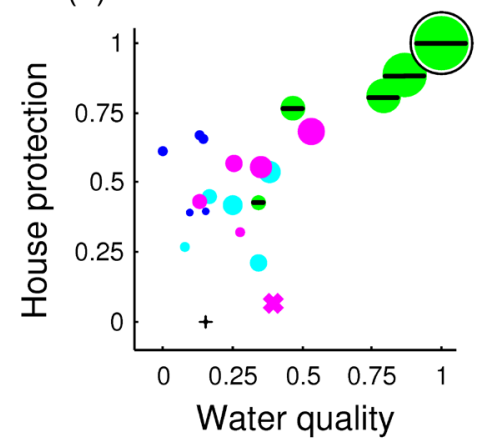

(c)

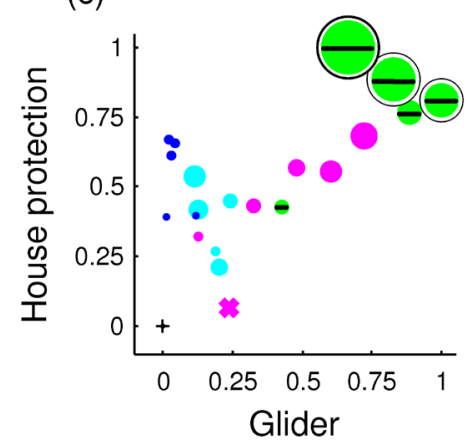

(e)

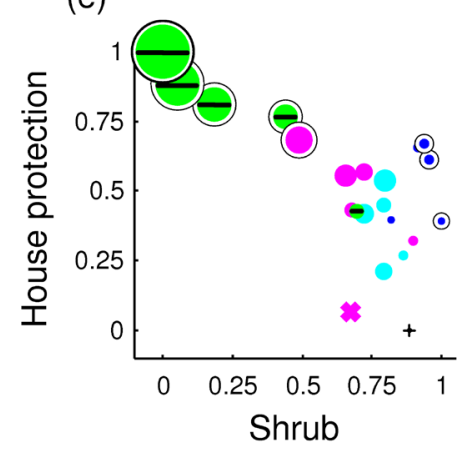

(g)

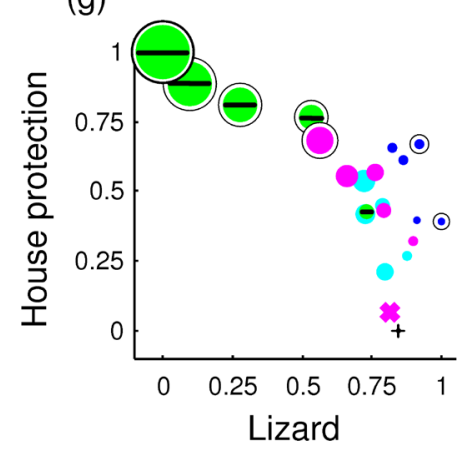

(b)

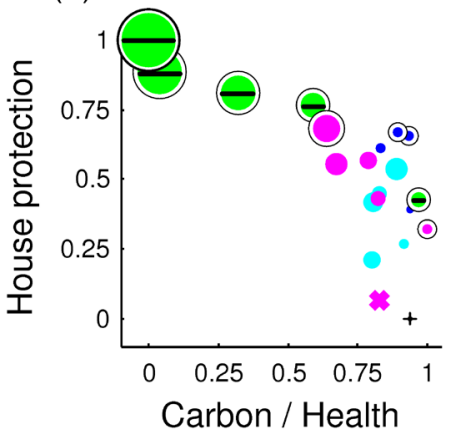

(d)

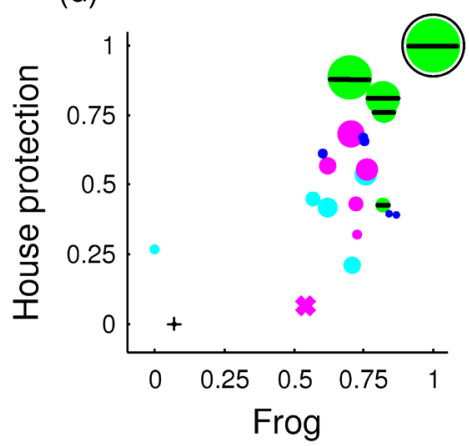

(f)

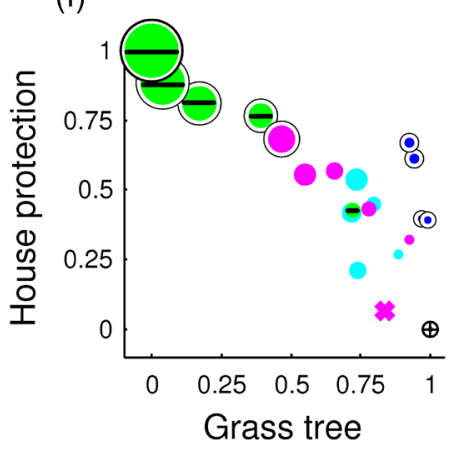

Pareto frontier

- None

- Edge

- Linear

- Constrained

- Unconstrained

* Current management

Fig. 2 
(a) Additive Utility Function

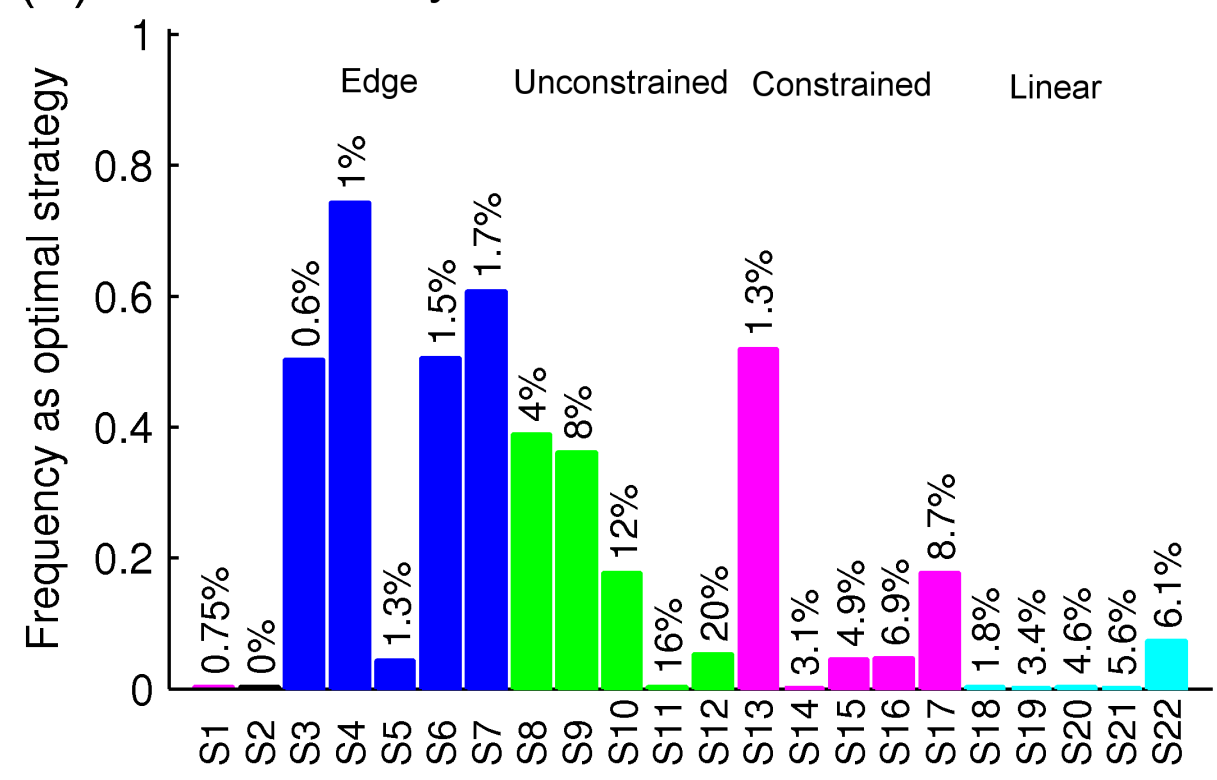

(b)Multiplicative Utility Function

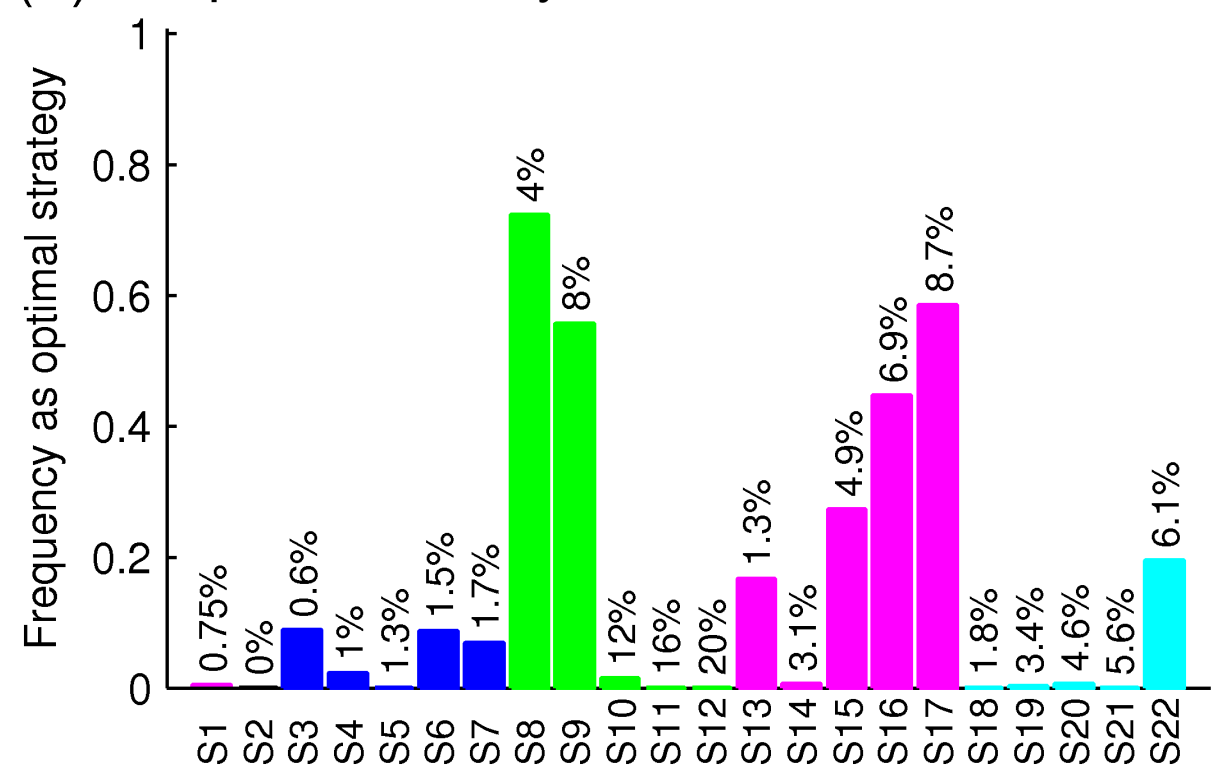

Management strategy

Fig. 3 


\begin{tabular}{|c|c|c|c|c|c|c|c|c|c|c|c|}
\hline $\begin{array}{c}\text { Scenario } \\
\text { code }\end{array}$ & $\begin{array}{l}\text { Burning } \\
\text { scenario }\end{array}$ & $\begin{array}{c}\text { Burning } \\
\text { effort }\end{array}$ & $\begin{array}{c}\text { Burning } \\
\text { area }\end{array}$ & $\begin{array}{l}\stackrel{y}{u} \\
\stackrel{\text { }}{0} \\
\text { 오 }\end{array}$ & $\frac{\bar{d}}{\frac{ \pm}{\pi}}$ & 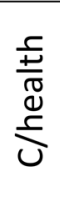 & $\frac{n}{\frac{n}{0}}$ & $\begin{array}{l}\mathscr{0} \\
\stackrel{0}{0} \\
\stackrel{5}{4}\end{array}$ & $\frac{\frac{n}{3}}{\frac{2}{2}}$ & 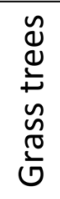 & $\begin{array}{l}\frac{0}{0} \\
\frac{N}{N} \\
\frac{N}{3}\end{array}$ \\
\hline 1 & Constr & $0.75 \%$ & 0.75 & 0 & 0 & 0 & 0 & 0 & 0 & 0 & 0 \\
\hline 2 & None & None & 0 & -1 & -1 & 1 & -1 & -1 & 1 & 1 & 0 \\
\hline 3 & Edge & $4 \%$ & 0.6 & 1 & -1 & 1 & -1 & 1 & 1 & 1 & 1 \\
\hline 4 & Edge & $8 \%$ & 1.0 & 1 & -1 & 1 & -1 & 1 & 1 & 1 & 1 \\
\hline 5 & Edge & $12 \%$ & 1.3 & 1 & -1 & 0 & -1 & 1 & 1 & 1 & 0 \\
\hline 6 & Edge & $16 \%$ & 1.5 & 1 & -1 & 1 & -1 & 1 & 1 & 0 & 0 \\
\hline 7 & Edge & $20 \%$ & 1.7 & 1 & -1 & 0 & -1 & 1 & 1 & 1 & 1 \\
\hline 8 & Uncons & $4 \%$ & 4.0 & 1 & -1 & 1 & 1 & 1 & 0 & -1 & 0 \\
\hline 9 & Uncons & $8 \%$ & 8.0 & 1 & 1 & -1 & 1 & 1 & -1 & -1 & -1 \\
\hline 10 & Uncons & $12 \%$ & 12.0 & 1 & 1 & -1 & 1 & 1 & -1 & -1 & -1 \\
\hline 11 & Uncons & $16 \%$ & 16.0 & 1 & 1 & -1 & 1 & 1 & -1 & -1 & -1 \\
\hline 12 & Uncons & $20 \%$ & 20.0 & 1 & 1 & -1 & 1 & 1 & -1 & -1 & -1 \\
\hline 13 & Constr & $4 \%$ & 1.3 & 1 & -1 & 1 & -1 & 1 & 1 & 1 & 1 \\
\hline 14 & Constr & $8 \%$ & 3.1 & 1 & -1 & 0 & 1 & 1 & 0 & 0 & 0 \\
\hline 15 & Constr & $12 \%$ & 4.9 & 1 & -1 & 0 & 1 & 1 & 0 & -1 & 0 \\
\hline 16 & Constr & $16 \%$ & 6.9 & 1 & -1 & -1 & 1 & 1 & 0 & -1 & -1 \\
\hline 17 & Constr & $20 \%$ & 8.7 & 1 & 1 & -1 & 1 & 1 & -1 & -1 & -1 \\
\hline 18 & Linear & $4 \%$ & 1.8 & 1 & -1 & 1 & -1 & -1 & 1 & 0 & 0 \\
\hline 19 & Linear & $8 \%$ & 3.4 & 1 & -1 & 0 & 0 & 0 & 1 & 0 & 0 \\
\hline 20 & Linear & $12 \%$ & 4.6 & 1 & -1 & 0 & -1 & 1 & 1 & -1 & 0 \\
\hline 21 & Linear & $16 \%$ & 5.6 & 1 & -1 & 0 & -1 & 1 & 0 & -1 & -1 \\
\hline 22 & Linear & $20 \%$ & 6.1 & 1 & 0 & 0 & -1 & 1 & 1 & -1 & -1 \\
\hline
\end{tabular}

Fig. 4 
Appendix S1. Calculating responses to fire simulations.

\section{Species types}

To assess implications of fire management actions on biodiversity conservation objectives, we selected five species types representing different life histories, trophic status, and fire responses from the Sydney region. These included two plant and three vertebrate species. In one plant species, adults are killed by fire and regeneration is entirely from seeds released after fire from woody fruits in the plant canopies (represented by the shrub Hakea constablei) (Fordham et al. 2012). In the second plant type, a majority of individuals survive fire by resprouting and episodic seedling recruitment may occur after fire-stimulated flowering (represented by the grass tree Xanthorrhoea resinosa) (Regan et al. 2011). The animals were: a frog with tadpoles that mature in streams and small water bodies and with adults that occupy burrows throughout the forested landscape (represented by Heleioporus australiacus, the Giant Burrowing Frog) (Penman et al. 2008a); a mammalian arboreal foliarivore that shelters and breeds in tree hollows (represented by Petaurus volans, the Greater Glider) (Lindenmayer et al. 1999; McCarthy \& Lindenmayer 1999), and a generalist insectivore reptile associated with tussock grasses, leaf litter and fallen timber (represented by Pseudemoia entrecasteauxii, a scincid lizard) (Irvin et al. 2003). Our species types therefore include a seeding plant that survives best under severe fire with intermediate fire return rates (hereafter shrub: H. constablei), a re-sprouting plant that survives best under infrequent, high severity fire (hereafter grass tree: $X$. resinosa), a mammal that performs poorly under high severity fire (hereafter glider: $P$. volans), a reptile that performs poorly under frequent fire of any severity (hereafter lizard: P. entrecasteauxii), and a frog that may be vulnerable to high severity fire (hereafter frog: H. australiacus).

\section{Population model structure}

A stage-structured matrix model based on annual time steps was constructed for each species in RAMAS/Metapop (Akçakaya \& Root 2005). The species-specific configuration of stages reflected different rates of survival, reproduction and/or resource use within their respective life cycles (Table S1). Environmental stochasticity was represented in the model by drawing survival and fecundity values for each year from lognormal and normal distributions, respectively. The means and standard deviations of the matrix elements were estimated from available literature (Bradstock et al. 1994; Irvin et al. 2003; McCarthy \& Lindenmayer 1999; Penman \& Lemckert 2007; Penman et al. 2008b; Regan et al. 2011). Fire responses were modelled using a catastrophe matrix that specified stage-specific multipliers of vital rates (plants) or abundance (animals) for each year in which a fire occurred. Separate catastrophe matrices were estimated for low fire intensity, in which shrubs were only scorched (approximately $<1,500 \mathrm{~kW} \cdot \mathrm{m}^{-1}$ ) and high intensity in which shrub height foliage was completely consumed (approximately $>1,500 \mathrm{~kW} \cdot \mathrm{m}^{-1}$ ). Density-dependence was represented using a scramble model for the skink, a contest model for the frog and glider, and log-linear resource functions for the plants when their populations exceeded carrying capacity (Akçakaya \& Root 2005). The plant density-dependence models were similar to those described by Keith et al. (2008). 
The models were configured for a single population occupying a $500 \times 500 \mathrm{~m}$ patch. Initial populations were set at carrying capacity (carrying capacity + tadpoles for the frog; + seedbank for the plants) with the distribution among stages reflecting expected population structure in the first year after a fire. For example, in Hakea constablei, all individuals were in the one-year-old seedling stage.

Twenty fire regime scenarios reflecting factorial combinations of fire interval length and fire intensity were modelled for each species. Fixed fire intervals of 5, 10, 15, 20, 25, 30, 35, 40, 45 and 50 years were modelled for each of the two fire intensity ranges described above. Each scenario was replicated in 1000 simulations starting in the first year after a fire. Species responses to each scenario were estimated by calculating the mean and standard error of percentage change in population size (excluding seeds and tadpoles) between the year preceding the first simulated fire and the year preceding the second simulated fire. The simulation output consisted of curves of change in population size for both fire intensities, as functions of possible inter-fire intervals.

These response curves were used to assess changes across the Blue Mountains case-study for each of the simulated landscape fire histories. Populations were initialised at their carrying capacity in all cells of suitable habitat at the beginning of each replicate landscape simulation, and their persistence over the following years in each cell was based on the simulated local fire history. For each cell, after each fire event, we calculated the proportional change in the population predicted by the modelled PVA responses, with the added constraint that increasing populations could not exceed their local carrying capacity. Our response variable was based on the proportion of cells across the landscape in which the population size dropped below an endangerment threshold (essentially a quasi-extinction threshold), averaged across the 50 stochastic replicates of the fire model. The endangerment threshold was based on IUCN Red List criterion A (the population size criterion) for the "Endangered" category: a $50 \%$ decline over three generations or 10 years, whichever is longer. Generation lengths for the animals, Hakea and Xanthorrhoea were three, 12.5 and 50 years respectively. The corresponding endangerment thresholds for these three taxa were $16.5 \%, 61.8 \%$ and $88.7 \%$ (respectively) of their initial abundance. The performance of a given management strategy was measured by the difference between the cell occupancy across the landscape under that strategy, and the lowest occupancy from the worst performing strategy (the worst management strategy therefore has a performance of zero).

\section{Probability of house loss}

An empirical model relating occurrence of high intensity crown fire to chance of house loss (Price \& Bradstock 2012) was used to model the consequences of each prescribed fire strategy. All houses within $0.25 \mathrm{~km}$ of each sample cell were located. Houses were presumed to be destroyed if fire intensity in the adjacent cell exceeded $10,000 \mathrm{kw} \mathrm{m}^{-1}$, with adjustment for the effects of slope, aspect and proportion of forest cover within one kilometre of each house (Price \& Bradstock 2013). The model was calibrated to produce house loss rates 
similar to historical levels. This calibration was based on the known relationship between loss and Forest Fire Danger Index for the region (Blanchi et al. 2010), and under the prescribed burning scenario equating to current management ( $0.75 \%$ annual treatment rate).

\section{Carbon Emissions/health effects}

We used the net change in biomass following each simulated fire, including planned and unplanned fires, as a surrogate measure of greenhouse gas emissions and health effects associated with smoke. Biomass accumulation was modelled using fuel accumulation curves for the eleven different vegetation types found in the region based on Olson (1963) with data from Conroy (1996), Van Loon (1977), and Cary (2002). Consumption of biomass was estimated for each fire recorded in each sampled cell using the methodology of Bradstock et al. (2012). This method is based on estimation of fire intensity via rate of fire spread and fine fuel consumption as specified in the McArthur Forest Fire Danger model (Gill et al. 1987). Consumption of coarse woody debris, tree crowns and bark was scaled against simulated fire intensity (Bradstock et al. 2012). Annual rates of carbon emitted from fires were estimated independently for each replicate simulation, based on the assumption that the mass of carbon emitted is half of the mass of biomass consumed (Bradstock et al. 2012). The resulting overall carbon emissions from a cell, given a particular fire event, can therefore be calculated from the fire intensity (I) and the Forest Fire Danger Index (FFDI) according to the formula:

$$
C_{E}=\sqrt{I /(2.48 \times F F D I)}
$$

We assume release of fine particulate matter will be in proportion to the amount of carbon released (Pereira et al. 2009; Ward \& Hardy 1991), and so we regard our carbon emissions index as an approximate indicator of health-effects (Johnston et al. 2012; Marlier et al. 2013).

\section{Water quality}

High intensity fires in eucalypt forests can increase the propensity for erosion by altering the water repellent characteristics and wettability of surface soils (Doerr et al. 2006; Shakesby et al. 2007). An increase in the occurrence and extent of relatively high intensity fires $(>1500$ $\mathrm{kW} \mathrm{m}^{-1}$ ) will therefore increase the potential for erosion and outwash into drinking water reservoirs used by the city of Sydney. The effects on stored water were equated with the number of pixels that burnt with high intensity on steep slopes $\left(>15^{\circ}\right)$ in water catchments located within two kilometers of the edge of water bodies. We assumed that high-intensity fires contributed to lower water quality at a linearly accumulating rate. Although this metric is not a quantification of water quality degradation, it will preserve the ranking of management actions that such a quantification would produce.

\section{References}

Akçakaya, H., and W. Root 2005. RAMAS GIS: Linking Landscape Data with Population Viability Analysis (version 5.0). Applied Biomathematics, Setauket, New York. 
Blanchi, R., C. Lucas, J. Leonard, and K. Finkele. 2010. Meteorological conditions and wildfire-related house loss in Australia. International Journal of Wildland Fire 19:914-926.

Bradstock, R. A., M. M. Boer, G. J. Cary, O. F. Price, R. J. Williams, D. Barrett, G. Cook, A. M. Gill, L. B. W. Hutley, H. Keith, S. W. Maier, M. Meyer, S. H. Roxburgh, and J. Russell-Smith. 2012. Modelling the potential for prescribed burning to mitigate carbon emissions from wildfires in fire-prone forests of Australia. International Journal of Wildland Fire 21:629-639.

Bradstock, R. A., A. M. Gill, S. M. Hastings, and P. H. R. Moore. 1994. Survival of serotinous seedbanks during bushfires - comparative-studies of Hakea species from southeastern australia. Australian Journal of Ecology 19:276-282.

Cary, G. J., and C. K. Golding 2002. Fuel Modelling for Fire Management: a Review for the Northern Directorate of the New South Wales National Parks and Wildlife Service. School of Resources, Environment and Society, Australian National University, Canberra.

Conroy, R. J. 1996. To burn or not to burn? A description of the history, nature and management of bushfires within Ku-Ring-Gai Chase National Park. Proceedings of the Linnean Society of New South Wales 116:79-95.

Doerr, S. H., R. A. Shakesby, W. H. Blake, C. J. Chafer, G. S. Humphreys, and P. J. Wallbrink. 2006. Effects of differing wildfire severities on soil wettability and implications for hydrological response. Journal of Hydrology 319:295-311.

Fordham, D. A., H. R. Akcakaya, M. B. Araujo, J. Elith, D. A. Keith, R. Pearson, T. D. Auld, C. Mellin, J. W. Morgan, T. J. Regan, M. Tozer, M. J. Watts, M. White, B. A. Wintle, C. Yates, and B. W. Brook. 2012. Plant extinction risk under climate change: are forecast range shifts alone a good indicator of species vulnerability to global warming? Global Change Biology 18:1357-1371.

Gill, A. M., K. R. Christian, P. H. R. Moore, and R. I. Forrester. 1987. Bushfire incidence, fire hazard and fuel reduction burning. Australian Journal of Ecology 12:299-306.

Irvin, M., M. Westbrooke, and M. Gibson 2003. Effects of repeated low-intensity fire on reptile populations of a mixed eucalypt foothill forest in south-eastern Australia, Research Report No. 65. Department of Sustainability and Environment, Melbourne, Victoria.

Johnston, F. H., S. B. Henderson, Y. Chen, J. T. Randerson, M. Marlier, R. S. DeFries, P. Kinney, D. M. J. S. Bowman, and M. Brauer. 2012. Estimated Global Mortality Attributable to Smoke from Landscape Fires. Environmental Health Perspectives 120:695-701.

Keith, D. A., H. R. Akcakaya, W. Thuiller, G. F. Midgley, R. G. Pearson, S. J. Phillips, H. M. Regan, M. B. Araujo, and T. G. Rebelo. 2008. Predicting extinction risks under climate change: coupling stochastic population models with dynamic bioclimatic habitat models. Biology Letters 4:560-563.

Lindenmayer, D. B., R. B. Cunningham, and M. A. McCarthy. 1999. The conservation of arboreal marsupials in the montane ash forests of the central highlands of Victoria, south-eastern Australia. VIII. Landscape analysis of the occurrence of arboreal marsupials. Biological Conservation 89:83-92. 
Marlier, M. E., R. S. DeFries, A. Voulgarakis, P. L. Kinney, J. T. Randerson, D. T. Shindell, Y. Chen, and G. Faluvegi. 2013. El Nino and health risks from landscape fire emissions in southeast Asia. Nature Climate Change 3:131-136.

McCarthy, M. A., and D. B. Lindenmayer. 1999. Incorporating metapopulation dynamics of greater gliders into reserve design in disturbed landscapes. Ecology 80:651-667.

Olson, J. S. 1963. Energy storage and the balance of producers and decomposers in ecological systems. Ecology 44:322-331.

Penman, T., and F. Lemckert. 2007. Heleioporus australiacus predation. Herpetological Review 38:185-186.

Penman, T., F. Lemckert, and M. Mahony. 2008a. Applied Conservation Management of a Threatened Forest Dependent Frog, Heleioporus australiacus. Endangered Species Research 5:45-53.

Penman, T. D., F. L. Lemckert, and M. J. Mahony. 2008b. Spatial ecology of the giant burrowing frog (Heleioporus australiacus): implications for conservation prescriptions. Australian Journal of Zoology 56:179-186.

Pereira, G., S. R. Freitas, E. C. Moraes, N. J. Ferreira, Y. E. Shimabukuro, V. B. Rao, and K. M. Longo. 2009. Estimating trace gas and aerosol emissions over South America: Relationship between fire radiative energy released and aerosol optical depth observations. Atmospheric Environment 43:6388-6397.

Price, O., and R. Bradstock. 2013. Landscape Scale Influences of Forest Area and Housing Density on House Loss in the 2009 Victorian Bushfires. Plos One 8.

Price, O. F., and R. A. Bradstock. 2012. The efficacy of fuel treatment in mitigating property loss during wildfires: Insights from analysis of the severity of the catastrophic fires in 2009 in Victoria, Australia. Journal of Environmental Management 113:146-157.

Regan, H. M., D. A. Keith, T. J. Regan, M. G. Tozer, and N. Tootell. 2011. Fire management to combat disease: turning interactions between threats into conservation management. Oecologia 167:873-882.

Shakesby, R. A., P. J. Wallbrink, S. H. Doerr, P. M. English, C. J. Chafer, G. S. Humphreys, W. H. Blake, and K. M. Tomkins. 2007. Distinctiveness of wildfire effects on soil erosion in south-east Australian eucalypt forests assessed in a global context. Forest Ecology and Management 238:347-364.

Van Loon, A. P. 1977. Bushland Fuel Quantities in the Blue Mountains - Litter and Understorey. Forestry Commission of NSW, Research Note No. 33, Sydney, NSW.

Ward, D. E., and C. C. Hardy. 1991. Smoke emissions from wildland fires. Environment International 17:117-134. 
Table S1.

Parameters used in models. Fecundity and transition probabilities are given by life stage, with both mean transition probability, and the standard deviation in parentheses. Multipliers indicate life stage and the multiplier applied to the population variable affected by fire.

\begin{tabular}{|c|c|c|c|c|c|}
\hline Functional Type & Obligate seeding shrub & Resprouting plant; grass tree & $\begin{array}{l}\text { Arboreal } \\
\text { mammal }\end{array}$ & Burrowing Frog & $\begin{array}{l}\text { Litter-dwelling } \\
\text { lizard }\end{array}$ \\
\hline $\begin{array}{l}\text { Species model } \\
\text { based on }\end{array}$ & Hakea constablei & Xanthorhoea resinosa & $\begin{array}{l}\text { Petaurus } \\
\text { volans }\end{array}$ & Heleioporus australis & $\begin{array}{l}\text { Pseudemoia } \\
\text { entrecasteauxii }\end{array}$ \\
\hline No. stages & 15 & 36 & 12 & 7 & 6 \\
\hline Fecundity & $\begin{array}{l}5-15 \text { respectively: } 0.2(0.04) \\
, 0.4(0.08), 1.0(0.2) \\
2.0(0.4), 4.0(0.8), 5.0(1.0) \\
6.0(1.2), 8.0(1.6), 12.0(2.4) \\
16.0(3.2), 6.0(1.2)\end{array}$ & 33-37: 0.000001 & 2-12: 0.25 & $\begin{array}{l}6: 50(10) \\
7: 150(30)\end{array}$ & $\begin{array}{l}3: 2(1) \\
4-6: 4(2)\end{array}$ \\
\hline $\begin{array}{l}\text { Transition } \\
\text { probabilities }\end{array}$ & $\begin{array}{l}\text { 1-1: } 0.8(0.16) \\
\text { 1-2: } 0.000001(0) \\
\text { 2-3-4: } 0.82(0.18) \\
\text { 4-5: } 0.9(0.01) \\
\text { 5-6-7-8-9: } 0.93(0.007) \\
\text { 9-10-11-12: } 0.99(0.001) \\
\text { 12-12: } 0.7(0.03) \\
\text { 12-13: } 0.29(0.029) \\
\text { 13-13: } 0.7(0.03) \\
\text { 13-14: } 0.29(0.029) \\
\text { 14-14: } 0.9(0.01) \\
\text { 14-15: } 0.09(0.009) \\
\text { 15-15: } 0.8(0.02)\end{array}$ & $\begin{array}{l}\text { 1-2: } 0.79(0.021) \\
\text { 2-3: } 0.81(0.019) \\
\text { 3-4: } 0.84(0.016) \\
\text { 4-5: } 0.9(0.01) \\
\text { 5-6: } 0.95(0.005) \\
\text { 6-7-8-9-10: } 0.99(0.001) \\
\text { 10-11, 10-31: } 0.5(0.05) \\
\text { 11-31 inclusive: } 0.995(0.0005) \\
\text { 31-31, 32-32: } 0.7(0.03) \\
\text { 32-33: } 0.295(0.0295) \\
\text { 33-33: } 0.985(0.0015) \\
\text { 33-34: } 0.005(0.0005) \\
\text { 33-36: } 0.005(0.0005) \\
\text { 34-34: } 0.98(0.002) \\
\text { 34-35, 34-36: } 0.005(0.0005) \\
\text { 35-35: } 0.985(0.0015) \\
\text { 35-36: } 0.005(0.0005) \\
\text { 36-36: } 0.7(0.03)\end{array}$ & $\begin{array}{l}1-2: 0.5 \\
(0.05) \\
2-12 \\
\text { inclusive: } \\
0.85(0.015) \\
12+: 0(0)\end{array}$ & $\begin{array}{l}\text { 1-2: } 0.01(0.002) \\
\text { 1-3: } 0.1(0.02) \\
\text { 2-3: } 0.1(0.02) \\
\text { 3-4-5: } 0.25(0.025) \\
\text { 5-6-7: } 0.5(0.05) \\
\text { 6-6: } 0.25(0.025) \\
\text { 7+: } 0.75(0.025)\end{array}$ & $\begin{array}{l}\text { 1-2: } 0.1(0.035) \\
2-3-4-5-6: 0.5 \\
(0.2) \\
6+: 0(0)\end{array}$ \\
\hline
\end{tabular}




\begin{tabular}{|c|c|c|c|c|c|}
\hline Initial abundance & 1000 & 1000 & 20 & 1800 & 4033 \\
\hline Max. growth rate & 1 & 1 & 1.2 & 1.2 & 1.2 \\
\hline Carrying Capacity & 199 & 199 & 20 & 200 & 4033 \\
\hline $\begin{array}{l}\text { Density } \\
\text { dependence type }\end{array}$ & Log-linear resource & Log-linear resource & Contest & Contest & Scramble \\
\hline $\begin{array}{l}\text { Population variable } \\
\text { affected by fire }\end{array}$ & Vital rates & Vital rates & Abundance & Abundance & Abundance \\
\hline $\begin{array}{l}\text { High intensity fire } \\
\text { survival \& growth } \\
\text { multipliers }\end{array}$ & $\begin{array}{l}\text { Seedbank: } 200000 \text {; all } \\
\text { other stages: } 0\end{array}$ & $\begin{array}{l}\text { 1,2: } 0 ; 3: 0.2 ; 4: 0.4 ; 5,6: 0.6 ; 7,8: \\
0.7 ; 9,10: 0.8 ; 11,14: 0.85 ; 15,24: \\
0.9 ; 25,30: 0.95 ; 31: 0.96 ; 32: \\
0.97 ; 33: 0.99 ; 34: 0.92 ; 35: 0.84 \\
\text { 36: } 0\end{array}$ & $\begin{array}{l}\text { Yr1: 0; Yr2- } \\
\text { 11: } 0.1 ; \text { Yr12: } \\
0\end{array}$ & $\begin{array}{l}1: 1.0 ; 2: 0.05 ; 3: 0.2 \\
4: 0.4 ; 5,6,7: 0.5\end{array}$ & All stages: 0.2 \\
\hline $\begin{array}{r}\text { High intensity fire } \\
\text { fecundity } \\
\text { multipliers }\end{array}$ & 0 & $\begin{array}{l}\text { 31: 104106600; 32: 291498500; } \\
\text { 33: 749567500; 34: 291498500; } \\
\text { 35: 749567500; 36: } 0\end{array}$ & NA & NA & NA \\
\hline $\begin{array}{r}\text { Low intensity fire } \\
\text { survival \& growth } \\
\text { multipliers }\end{array}$ & $\begin{array}{l}\text { Seedbank: } 100000 ; \text { all } \\
\text { other stages: } 0\end{array}$ & $\begin{array}{l}\text { 1,2: 0; 3: 0.2; 4: 0.4; 5: 0.6; 6: 0.7; } \\
\text { 7: 0.75; 8: 0.8; 9: 0.85; 10,14:0.9; } \\
\text { 15,20: 0.95; 21,30: 0.99; 31: 0.99; } \\
\text { 32: 0.99; 33: 0.99; 34: 0.99; 35: } \\
\text { 0.99; 36: } 0\end{array}$ & Yr1-12:0.5 & $\begin{array}{l}1: 0.75 ; 2: 0.75 ; 3: \\
0.9 ; 4,5,6: 0.95\end{array}$ & All stages: 0.2 \\
\hline $\begin{array}{r}\text { Low intensity fire } \\
\text { fecundity } \\
\text { multipliers }\end{array}$ & 0 & $\begin{array}{l}\text { 31: 10411; 32: 29150; 33: 74957; } \\
\text { 34: 21150; 35: 75957; 36: } 0\end{array}$ & NA & NA & NA \\
\hline Suitable habitat & $\begin{array}{l}\text { Heathlands, Dry Sclerophyll } \\
\text { Forests }\end{array}$ & $\begin{array}{l}\text { Heathlands, Dry Sclerophyll } \\
\text { Forests (shrubby subformation) }\end{array}$ & $\begin{array}{l}\text { Dry } \\
\text { Sclerophyll } \\
\text { and Wet } \\
\text { Sclerophyll } \\
\text { Forests }\end{array}$ & $\begin{array}{l}\text { Heathlands, Dry } \\
\text { Sclerophyll Forests }\end{array}$ & $\begin{array}{l}\text { Dry Sclerophyll } \\
\text { and Wet } \\
\text { Sclerophyll } \\
\text { Forests, } \\
\text { Forested } \\
\text { Wetlands }\end{array}$ \\
\hline
\end{tabular}


Figure S1. Changes in abundance in response to inter-fire intervals for five species types. Orange lines indicate the response to a low intensity fire $(<1500 \mathrm{~kW} / \mathrm{m})$; red lines indicate the response to high intensity fires. Lines show linear interpolations of the simulations from stage-structured matrix population viability models (black dots). Note that the response of the lizard is insensitive to fire intensity, and the two lines are therefore overlaid. Although a fire return interval of zero is not possible, we extrapolate back to zero to illustrate possible effects of return intervals less than five years.

In the population model, the arboreal mammal (glider), was extremely sensitive to high intensity fire, but insensitive to low intensity fire (a). The frog declined with high fire frequency, but high intensity fire had a stronger negative effect than low intensity fire (b). High intensity fire generally promoted the abundance of the two plant species more than low intensity fire (c, d). Populations of the obligate seeding shrub increased most rapidly with intermediate fire intervals (c), while those of the resprouting grass tree suffered substantial declines under low intensity fire and longer inter-fire intervals (d). The lizard declined in abundance with short fire intervals of any intensity (e)

\section{(a) Glider}

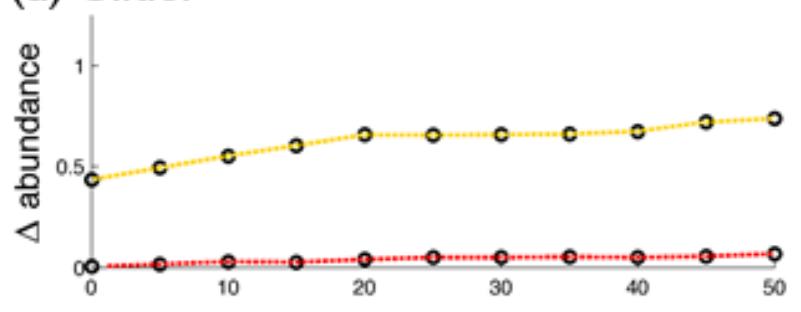

(b) Frog

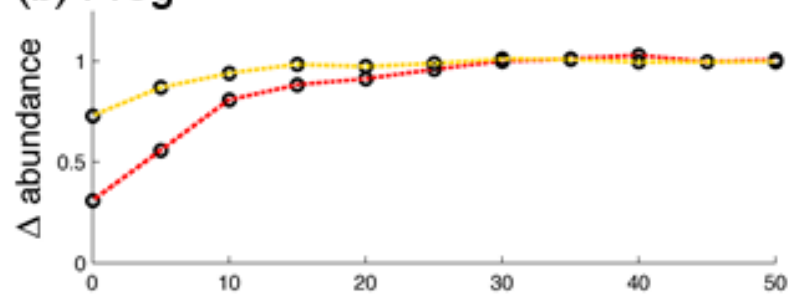

(c) Shrub

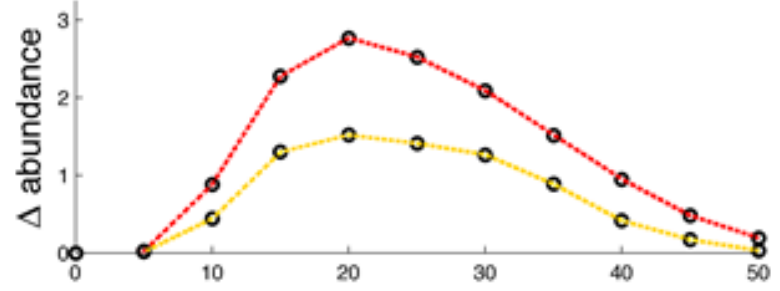

(d) Grass tree

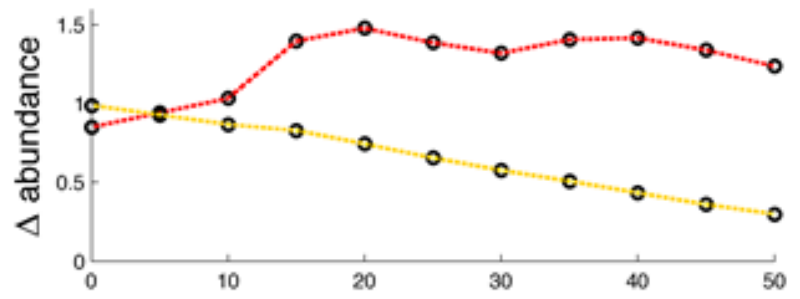

(e) Lizard

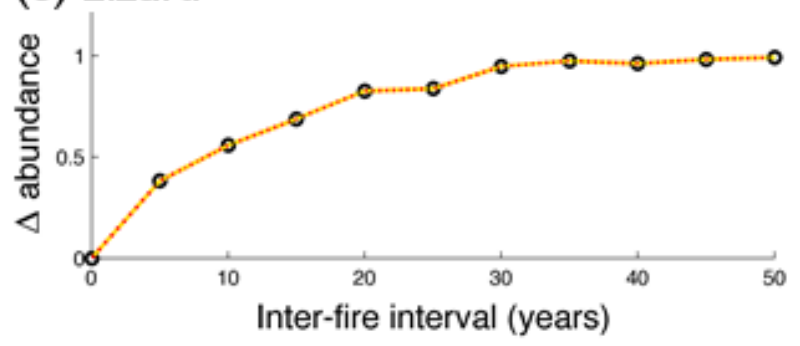


1 Figure S2. Pairwise Pareto surfaces for eight objectives. Axes are scaled from 0 (worst

2 performing scenario) to 1 (best performing scenario). Thus: Carbon/Health $=$ Reduction in

$3 \mathrm{CO}_{2}$ and particulate emissions; House protect $=$ Reduction in house losses; Water $=$ Water

4 quality; Animal and plant species $=$ Final regional distribution as a proportion of initial

5 distribution. The marker color denotes the spatial pattern of prescribed burning (black = no

6 burn; dark blue $=$ edge; green $=$ unconstrained; pink $=$ constrained; light blue $=$ linear; pink

7 cross $=$ current management). Marker radius is proportional to the percentage of the study

8 region that was prescribed burnt (Fig. 2).
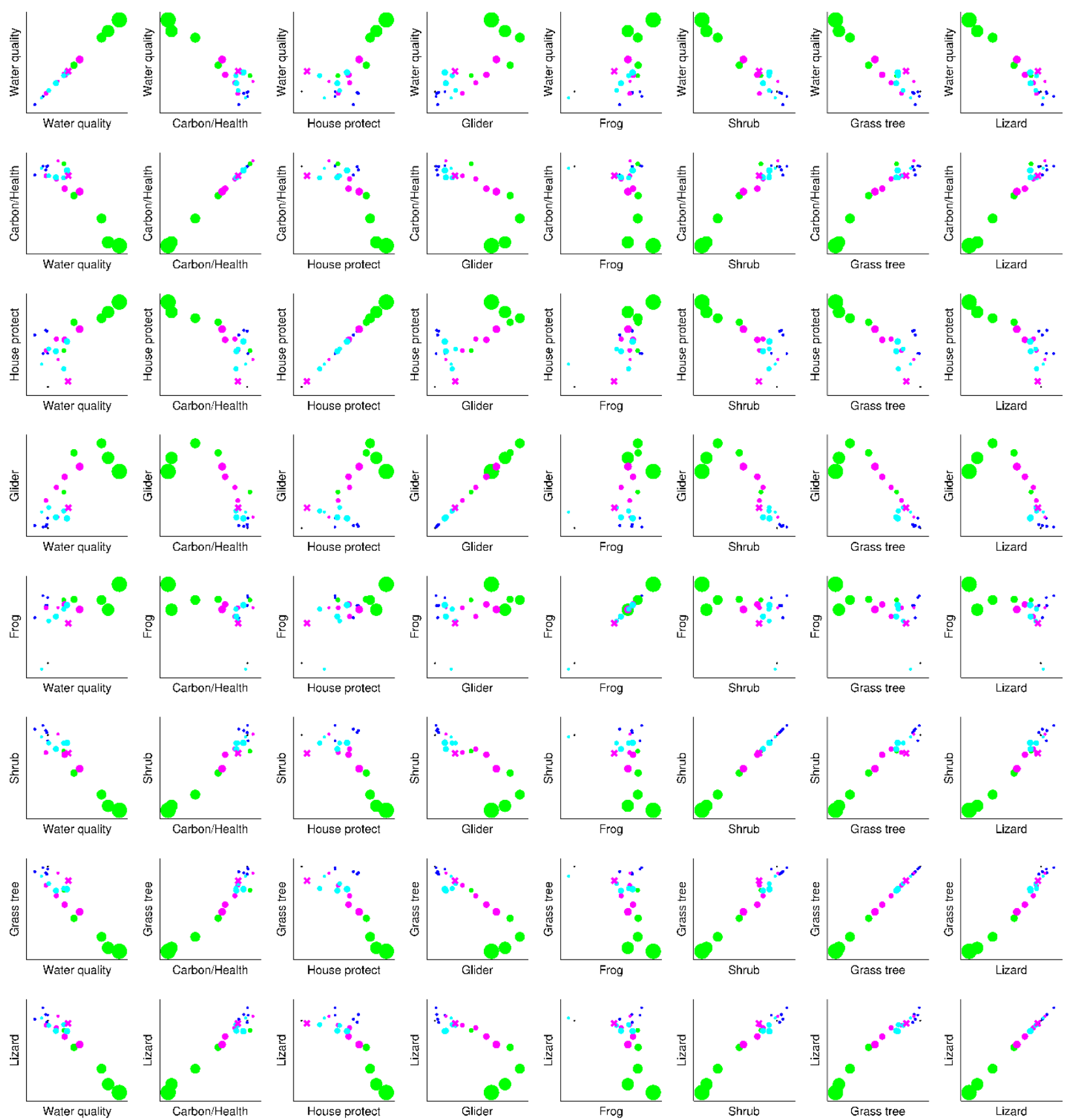
11 Figure S3. The slope of trade-offs against house loss (base case from main text shown with 12 circles) could be reduced by management that reduced the risk of houses burning by $50 \%$

13 (shown with square markers). All of the circular markers are dominated by their square

14 counterparts. The location of each marker indicates the outcomes for each objective, where

15 axes are scaled from 0 (worst performing scenario) to 1 (best performing scenario). Marker

16 color indicates the spatial pattern of prescribed burning (black = no burn; dark blue = edge;

17 green $=$ unconstrained; pink $=$ constrained; light blue $=$ linear; pink cross $=$ current

18 management). The radius or side length of the marker is proportional to the percentage of the

19 habitat that experienced prescribed burning (Fig. 2).

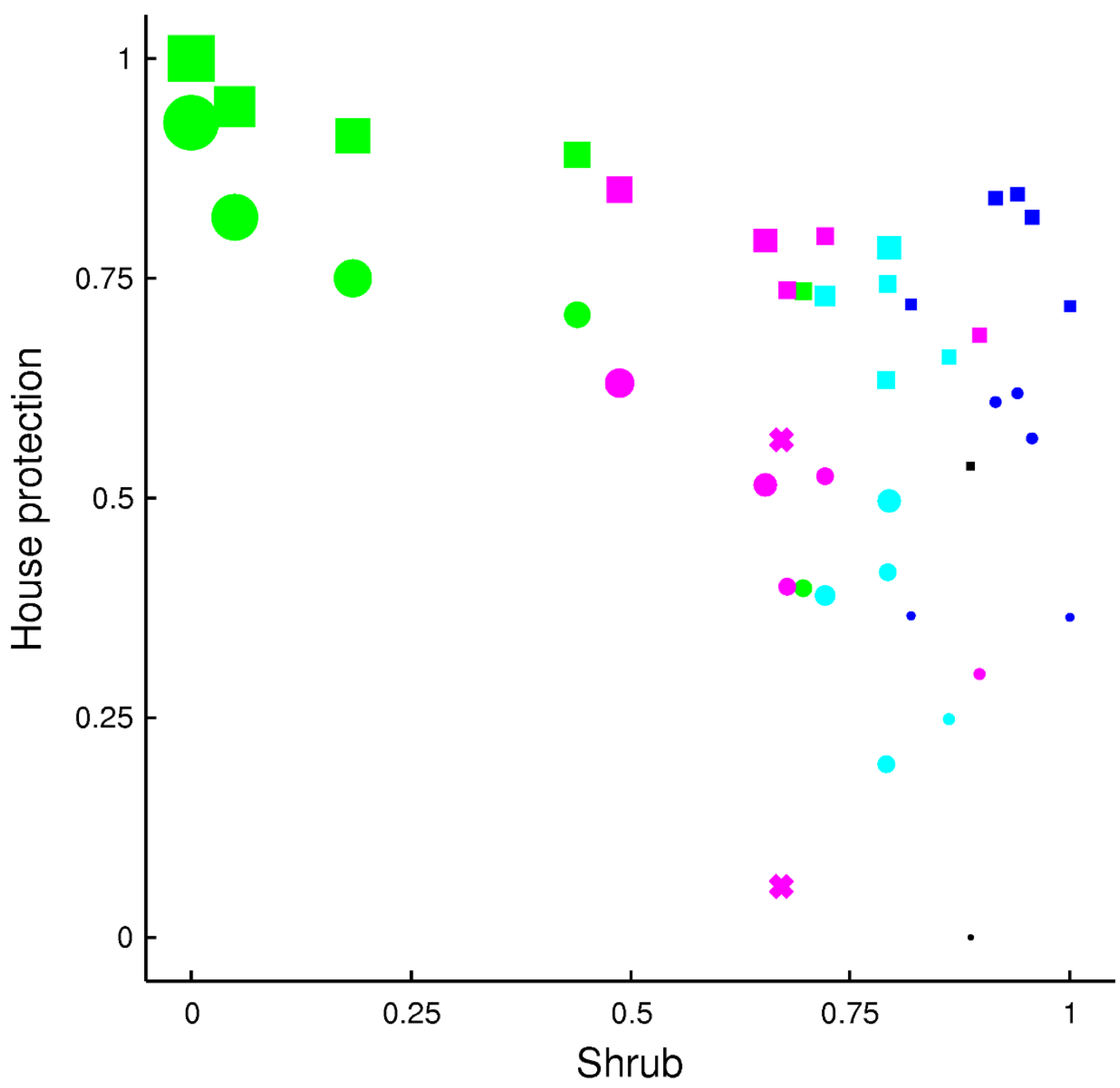


21 Figure S4. Pareto surfaces comparing house protection with seven other objectives when fire simulation stochasticity is included. The location of each marker indicates the outcomes for each objective, where axes are scaled from 0 (worst performing scenario) to 1 (best performing scenario). Thus: Carbon/Health = Reduction in emissions; House protection = Reduction in house losses; Animal and plant species types $=$ Change in regional distribution relative to initial distribution. The marker color denotes the spatial pattern of prescribed burning, as indicated by the legend. The radius of the marker is proportional to the percentage of the habitat that experienced prescribed burning (i.e., larger markers correspond to strategies with more prescribed burning). The lines that intersect each marker encompass $95 \%$ of the 50 different realisations of the fire simulation. The bounds are constructed for each objective independently.

(a)

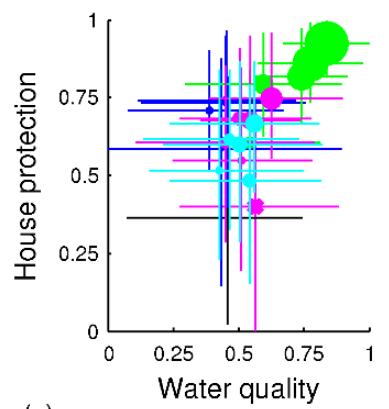

(c)

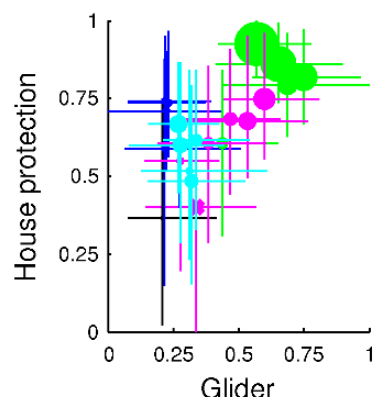

(e)

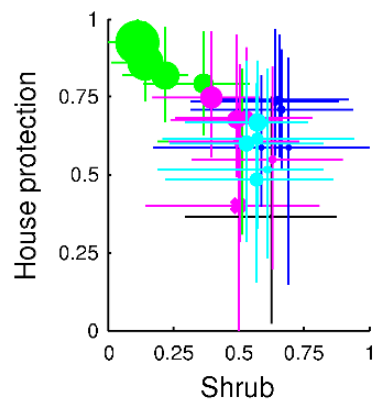

(g)

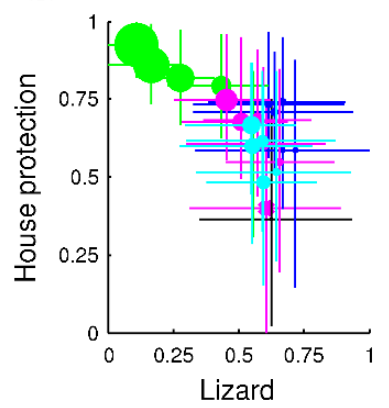

(b)

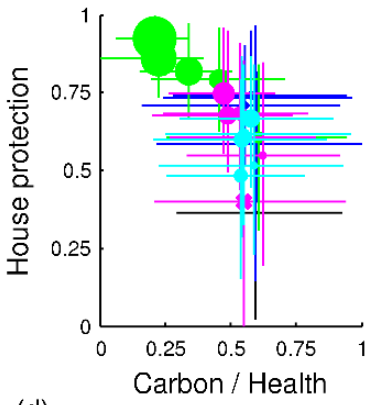

(d)

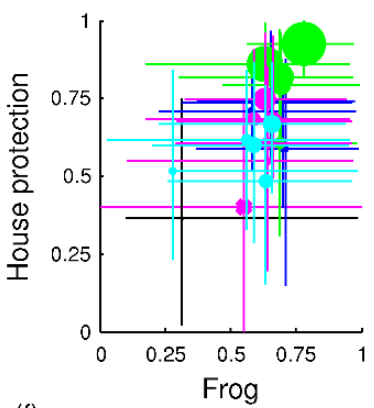

(f)

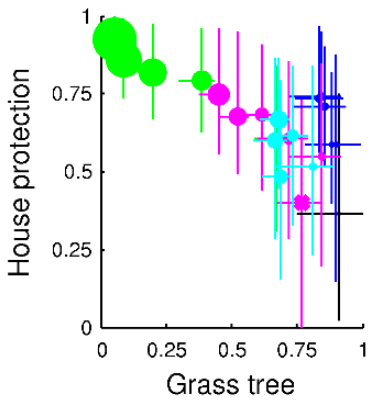

None

Edge

- Linear

Constrained

- Unconstrained

* Current management 
Figure S5. Robust decision making analysis indicating the robustness of management actions to variation in the weighting of the utility function, and to stochasticity in the fire simulations. In each iteration of our analysis, we chose a set of weightings and one of the fire simulations at random, and calculated the utility for each objective. The response variable for each objective was whether or not the management scenario generated utility that was within $5 \%$ of the maximum utility offered. We repeated this procedure 10,000 times, and constructed frequency distributions for both the (a) additive and (b) multiplicative utility functions.

Scenarios were color coded by the spatial pattern of burning as in Fig. A3, and were labelled by the percentage of the region that was prescribe burned.

\section{(a) Additive Utility Function}

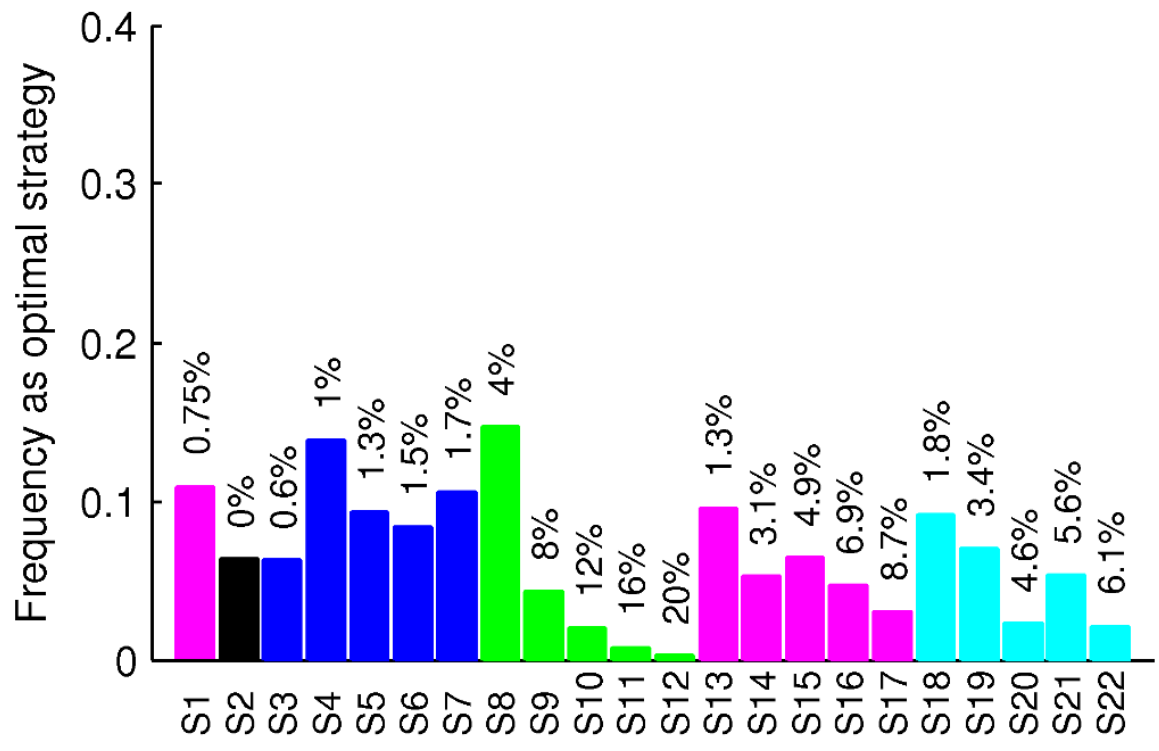

\section{(b) Multiplicative Utility Function}

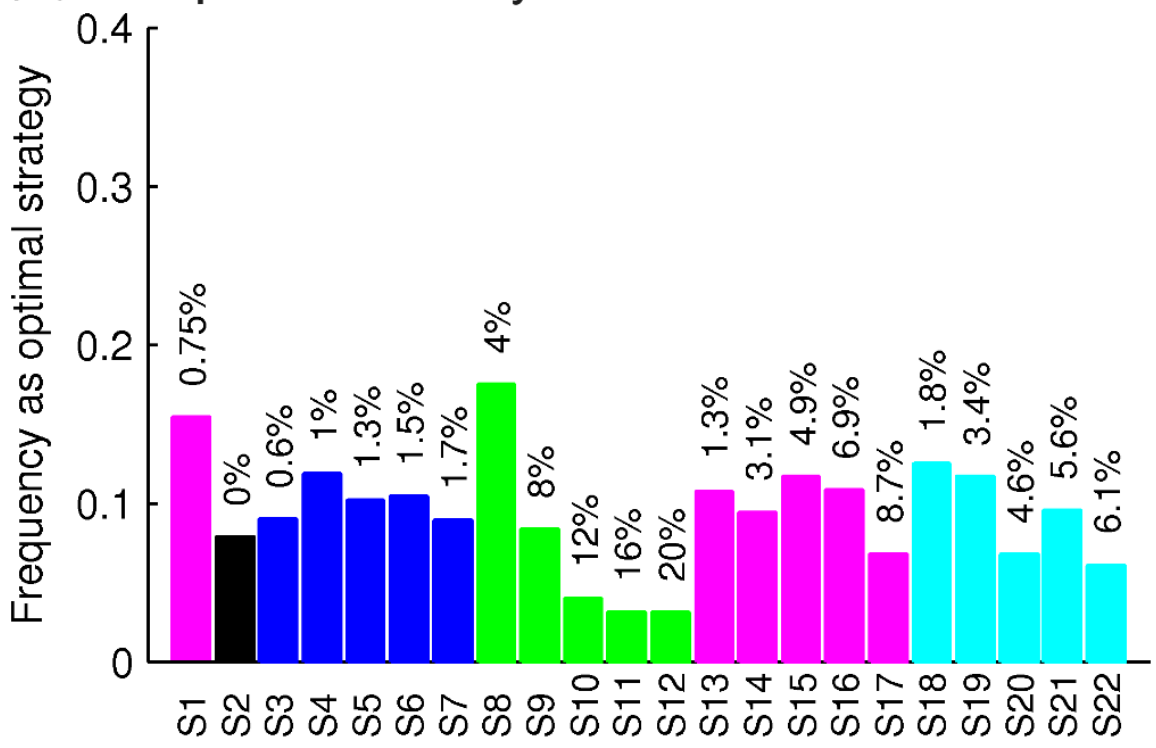

Management strategy 
Figure S6. Mutually acceptable outcomes for management scenarios (rows show management scenarios), according to a set of eight objectives (columns), accounting for variation caused by stochastic fire simulations. Management actions either improve (dark green), reduce (orange), or have no effect on (white) the utility function, compared with the current management strategy (strategy 1). Improvements or reductions are more than $10 \%$ different from current performance, in at least $75 \%$ of bootstrap resamples. Bootstrap resamples are taken with replacement from the 50 stochastic fire simulations in the Blue Mountains dataset. Burning effort is the annual area treated as a percentage of the area of blocks available for burning according to the burning strategy. Burning area is this area as a percentage of the Blue Mountains study region. Burning strategies: Edge (treatment of urban edge blocks only); Unconstrained (random selection of blocks irrespective of proximity to the urban interface); Constrained (selection of 'edge' and non-edge blocks on an evenly weighted basis) and; Linear (arrays of blocks arranged in intersecting north-south and east-west linear segments). Scenario 1 is the current strategy being applied in the Blue Mountains.

\begin{tabular}{|c|c|c|c|c|c|c|c|c|c|c|c|}
\hline $\begin{array}{l}\text { Scenario } \\
\text { code }\end{array}$ & $\begin{array}{l}\text { Burning } \\
\text { scenario }\end{array}$ & $\begin{array}{c}\text { Burning } \\
\text { effort }\end{array}$ & $\begin{array}{c}\text { Burning } \\
\text { area }\end{array}$ & 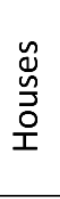 & 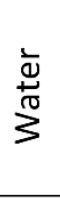 & 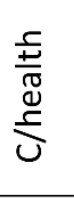 & $\frac{\stackrel{n}{\frac{\pi}{0}}}{\frac{.0}{0}}$ & $\begin{array}{l}\text { 品 } \\
\text { ㄴํㄴ }\end{array}$ & 管 & 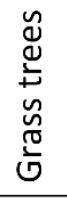 & $\begin{array}{l}\frac{n}{0} \\
\frac{N}{\pi} \\
\stackrel{N}{I}\end{array}$ \\
\hline 1 & Constr & $0.75 \%$ & 0.75 & 0 & 0 & 0 & 0 & 0 & 0 & 0 & 0 \\
\hline 2 & None & None & 0 & 0 & 0 & 0 & 0 & 0 & 0 & 0 & 0 \\
\hline 3 & Edge & $4 \%$ & 0.6 & 0 & 0 & 0 & 0 & 0 & 0 & 0 & 0 \\
\hline 4 & Edge & $8 \%$ & 1.0 & 0 & 0 & 0 & 0 & 0 & 0 & 0 & 0 \\
\hline 5 & Edge & $12 \%$ & 1.3 & 0 & 0 & 0 & 0 & 0 & 0 & 0 & 0 \\
\hline 6 & Edge & $16 \%$ & 1.5 & 0 & 0 & 0 & 0 & 0 & 0 & 0 & 0 \\
\hline 7 & Edge & $20 \%$ & 1.7 & 0 & 0 & 0 & 0 & 0 & 0 & 0 & 0 \\
\hline 8 & Uncons & $4 \%$ & 4.0 & 0 & 0 & 0 & 0 & 0 & 0 & 0 & 0 \\
\hline 9 & Uncons & $8 \%$ & 8.0 & 0 & 0 & 0 & 0 & 0 & 0 & -1 & 0 \\
\hline 10 & Uncons & $12 \%$ & 12.0 & 0 & 0 & 0 & 1 & 0 & 0 & -1 & 0 \\
\hline 11 & Uncons & $16 \%$ & 16.0 & 1 & 0 & 0 & 0 & 0 & 0 & -1 & -1 \\
\hline 12 & Uncons & $20 \%$ & 20.0 & 1 & 0 & 0 & 0 & 0 & -1 & -1 & -1 \\
\hline 13 & Constr & $4 \%$ & 1.3 & 0 & 0 & 0 & 0 & 0 & 0 & 0 & 0 \\
\hline 14 & Constr & $8 \%$ & 3.1 & 0 & 0 & 0 & 0 & 0 & 0 & 0 & 0 \\
\hline 15 & Constr & $12 \%$ & 4.9 & 0 & 0 & 0 & 0 & 0 & 0 & -1 & 0 \\
\hline 16 & Constr & $16 \%$ & 6.9 & 0 & 0 & 0 & 0 & 0 & 0 & -1 & 0 \\
\hline 17 & Constr & $20 \%$ & 8.7 & 0 & 0 & 0 & 0 & 0 & 0 & -1 & 0 \\
\hline 18 & Linear & $4 \%$ & 1.8 & 0 & 0 & 0 & 0 & 0 & 0 & 0 & 0 \\
\hline 19 & Linear & $8 \%$ & 3.4 & 0 & 0 & 0 & 0 & 0 & 0 & 0 & 0 \\
\hline 20 & Linear & $12 \%$ & 4.6 & 0 & 0 & 0 & 0 & 0 & 0 & 0 & 0 \\
\hline 21 & Linear & $16 \%$ & 5.6 & 0 & 0 & 0 & 0 & 0 & 0 & 0 & 0 \\
\hline 22 & Linear & $20 \%$ & 6.1 & 0 & 0 & 0 & 0 & 0 & 0 & 0 & 0 \\
\hline
\end{tabular}


